\title{
PROTECCIÓN DE LOS NIÑOS SEGÚN EL DERECHO INTERNACIONAL HUMANITARIO. UN BREVE RECUENTO DESDE LOS CONVENIOS DE GINEBRA HASTA EL DESAFÍO ACTUAL DE LA CORTE PENAL INTERNACIONAL
}

\begin{abstract}
Alfonso Manuel CHACÓN MATA*
RESUMEN: Este artículo tiene el propósito de realizar un recuento cronológico de las principales fases jurídicas que se han dado dentro del sistema de protección internacional humanitario, para tutelar a los menores en estado de riesgo con ocasión de un conflicto armado internacional e interno. Haremos un repaso de los mecanismos existentes inicialmente dentro de los denominados Convenios de Ginebra y sus respectivos protocolos, pasando por la Organización de las Naciones Unidas, los convenios y resoluciones internacionales y regionales existentes en esta materia hasta abordar con especial énfasis lo establecido dentro de la Corte Penal Internacional, de reciente fecha de constitución.

ABSTRACT: The intent of this article is to outline a chronological account of the main legal phases enacted to protect minors at risk within the humanitarian system of international protections during internal or international armed conflicts. Initally this review article will examine the Geneva Agreements and their respective protocols. Next, United Nation international resolutions and regional agreements will be analyzed. Finally, special emphasis on recent ruling by the International Penal Court will be discussed.

RÉSUMÉ: Cet article a le but d'effectuer un compte chronologique des principales phases juridiques qui ont été données dans le système de protection internationale humanitaire, pour protéger aux mineurs en état de risque à l'occasion d'un conflit armé international comme interne. Nous ferons un examen des mécanismes existants initialement dans les appelées Conventions de Genève et leurs protocoles respectifs, en passant par l'Organisation des Nations Unies, les conventions et les résolutions internationales et régionales existantes dans cette matière jusqu'à aborder avec une emphase spéciale ce qui est établi dans la Coupe Pénale Internationale, de récente date de constitution.
\end{abstract}

* Licenciado en derecho por la Universidad de Costa Rica (1999), diplomado en derechos humanos por la Universidad Alcalá de Henares, España (2002), master en derecho del trabajo y la seguridad social, UNED (2005), profesor en la Universidad Católica de Costa Rica, y del Programa de Maestría en Derechos Humanos del Instituto de Estudios Latinoamericanos de la Universidad Nacional. 
A Elizabeth Odio Benito, ex jueza del Tribunal de Crímenes de Guerra de la antigua Yugoslavia. Por su ejemplo de búsqueda de la justicia y respeto a la dignidad humana ... por ser guia e inspiración para los que creemos en los derechos humanos sin distingo de raza, credo o condición análoga.

\begin{abstract}
SUMARIO: I. Introducción. II. Los (as) niños (as) como sujetos sociales, merecedores de la tutela de derechos connaturales a su existencia. III. La tutela de la niñez en el DIH. Aplicación y vigencia de instrumentos internacionales. IV. Necesidad de una instancia jurisdicional de juzgamiento de las normas del DIH en favor de los grupos vulnerables. La Corte Penal Internacional. V. Consideraciones finales. VI. Bibliografia.
\end{abstract}

\title{
I. INTRODUCCIÓN
}

Este trabajo pretende esbozar algunos lineamientos generales en torno al quehacer del derecho internacional humanitario actual, y su relación con una población sumamente frágil: los niños y niñas que sufren las secuelas de los conflictos armados. Pretendemos demostrar que el desarrollo de esta disciplina jurídica de carácter humanitario, está priorizando la protección de los grupos más vulnerables como lo son en el caso que nos ocupan, los menores de edad, no sólo con los antecedentes jurisprudenciales de los tribunales especializados - como serían los casos de los Tribunales Internacionales de Crímenes de Guerra-, sino que además con la reciente adopción de la Corte Penal Internacional o también conocida como el Estatuto de Roma.

En aras de llegar a la anterior conclusión, nos valdremos de una descripción sucinta de los basamentos que sustentan el derecho internacional humanitario contemporáneo, así como las principales disposiciones normativas que regulan los derechos inalienables y connaturales de la infancia como categoría de especial protección. Consideramos, al igual que lo dicho por un teórico de los derechos de la niñez, que "La realización de los derechos humanos de los niños y de los adolescentes es el eje de un 
proyecto de sociedad"; 1 por esta razón vemos con optimismo que la comunidad internacional se encamine a salvaguardar el interés de aquellos que por su indefensión, les son "invisibilizados" sus derechos de optar por una vida digna y de pleno desarrollo de sus potencialidades.

La doctrina de la intervención humanitaria, tal como fuera propuesta por el jurista Hugo Grocio en el siglo XVII, reconoce el derecho de uno o más Estados de adoptar medidas, incluyendo el uso de la fuerza militar, para detener violaciones manifiestas a los derechos fundamentales de los individuos por parte del Estado de su nacionalidad. ${ }^{2}$ Se suele considerar 1864 como la fecha de nacimiento del derecho internacional humanitario - año en el que fue concretado el primer convenio de Ginebra-, aunque ya las disposiciones de ese derecho existían a nivel consuetudinario desde aproximadamente 1000 a. C. ${ }^{3}$ A partir del Convenio de Ginebra de 1864, de la Declaración de San Petersburgo de 1868 y los Convenios de La Haya en 1899 y 1907, el derecho de guerra se asienta en el campo del derecho internacional convencional, hacia presupuestos bien articulados: la protección internacional de las víctimas de conflictos armados y la limitación de los medios y métodos de combate. ${ }^{4}$ De esta "convencionalidad" del derecho que pueden tener los países para desplegar una guerra, se derivan los principios denominados Jus ad bellum (derecho a la guerra o normas que rigen el recurso a la guerra) y el Jus in bello (derecho en la guerra o normas que rigen la conducción de las hostilidades), ${ }^{5}$ que deben regir en una contienda de esta naturaleza. Entramos en este momento a catalogar qué entendemos por derecho internacional humanitario (DIH),

1 Baratta, Alessandro, "Situación de la protección de los derechos del niño", en Nieto Navia, Rafael (ed.), Estudios básicos de derechos humanos, San José, Costa Rica, Unión Europea-Instituto Interamericano de Derechos Humanos, 1994, vol. II, p. 14.

2 Buergenthal, Thomas et al., Manual internacional de derechos humanos, Caracas-San José, Costa Rica, Instituto Interamericano de Derechos Humanos-Editorial Jurídica Venezolana, 1990, p. 10.

3 Swinarski, Christophe, Introducción al derecho internacional humanitario, Costa Rica, Instituto Interamericano de Derechos Humanos, 1994, p. 7. Véase en igual sentido a Pictet, Jean, Desarrollo y principios del derecho internacional humanitario, Ginebra, Instituto Henry Durant, 1986, pp 13-37; Buergenthal et al., op. cit., nota anterior, p. 16.

4 Swinarski, op. cit., nota anterior, p. 9.

5 Grossrieder, Jacques, "El derecho internacional humanitario", Instituto Internacional de Derechos Humanos, 26a. Sesión de Enseñanza, Estrasburgo, julio de 1996, p. 36. 
en razón de que se constituye en la rama o materia jurídica que invocaremos en este ensayo de fundamentación.

Algunos autores han relacionado al DIH con el derecho que protege a las personas en una época de guerra. ${ }^{6}$ Otros autores manifiestan que no sólo basta esta situación de tutela, sino que además la misma debe hacerse en el más estricto apego a los derechos humanos. En este último sentido, Buergenthal aduce que el derecho humanitario en general puede ser definido como "el elemento de derechos humanos del derecho de la guerra". ${ }^{7}$ Para la ex jueza del Tribunal Internacional de Crímenes de Guerra de la antigua Yugoslavia, Elizabeth Odio Benito, "el derecho internacional humanitario es, conforme a la doctrina más generalizada, el conjunto de normas que protegen el núcleo básico de los derechos fundamentales de todos los seres humanos durante los conflictos armados". ${ }^{8}$

Esta aparente bifurcación entre el DIH y los derechos humanos es también motivo de análisis dentro de la doctrina más especializada. Se ha dicho que entre ambos existe una relación de complemento ${ }^{9}$ e incluso

6 En este sentido, para Pictet: "El derecho internacional humanitario es esa considerable posición del derecho internacional público que se inspira en el sentimiento de humanidad y que se centra en la protección de la persona en caso de guerra", en Pictet, Jean, op. cit., nota 3, p. 9. Para Swinarski: "El derecho internacional humanitario es el cuerpo de normas internacionales, de origen convencional o consuetudinario, específicamente destinado a ser aplicado en los conflictos armados, internacionales o no internacionales, y que limita, por razones humanitarias el derecho de las parte en conflicto a elegir libremente los métodos y los medios utilizados en la guerra, o que protege a las personas y a los bienes afectados, o que pueden estar afectados, por el conflicto", Swinarski, op. cit., nota 3, p. 11; véase en igual sentido a Schindler, Dietrich, "El Comité Internacional de la Cruz Roja y los derechos humanos", Revista Internacional de la Cruz Roja, enero-febrero de 1979, p. 3.

7 Buergenthal, Thomas, International Human Rights, St. Paul, Minnesota, West Publishing Co., 1995, p. 249.

8 Odio Benito, Elizabeth, "De la violación y otras graves agresiones a la integridad sexual como crímenes sancionados por el derecho internacional humanitario (crímenes de guerra)", en González Volio, Lorena (ed.), Ensayos en honor a Fernando Volio Jiménez, San José, Costa Rica, Instituto Interamericano de Derechos Humanos, 1998, p. 266.

9 Véase en este sentido a Swinarski, op. cit., nota 3, p. 17; y a Geiger, Louis, "Fuerzas armadas y respeto del derecho internacional humanitario: problemática", en Dalwankan, Unesh y Comité Internacional de la Cruz Roja (CICR), Simposio sobre Acción Humanitaria y Operaciones de Mantenimiento de la Paz, Ginebra, del 22 al 24 de junio 1994, p. 66. Para el profesor Dietrich Schindler: "la convergencia del derecho internacional humanitario y de los derechos humanos contribuye a mostrar que la guerra 
Gros Espiell ha ido más allá, al encontrar puntos de encuentro entre estos tipos de derechos aludidos con otro tipo de derecho, como es el derecho de los refugiados. ${ }^{10}$ Desde nuestra perspectiva, podemos acotar que los derechos humanos tienen un significado preciso para el DIH, pues tratándose de la dignidad humana en todas sus manifestaciones, la vida misma y hasta el derecho a la libertad que son necesarios observar dentro del $\mathrm{DIH}$, los derechos humanos se constituyen per se en un referente urgente para valorar el flagelo o irrespeto para quienes se encuentren inmersos dentro de los alcances del derecho que tienen las personas participantes o no en una determinada guerra.

Por esta razón, definiremos al DIH como la salvaguarda jurídica de naturaleza humanista y protectiva de los derechos humanos más elementales, que poseen todas aquellas personas sin discriminación alguna, vinculadas a un conflicto armado sea internacional o de carácter endógeno. De igual manera, este DIH se ha valido de una serie de principios que representan el mínimo de humanidad aplicable en todo tiempo, en todo lugar y en toda circunstancia, los cuales son válidos incluso para los

y la paz, las guerras civiles y los conflictos internacionales, el derecho internacional y el derecho interno son más interdependientes. El derecho de la guerra y el derecho de la paz, el derecho internacional y el derecho interno, cuyos ámbitos de aplicación estaban, en su origen, claramente separados, son hoy, a menudo, aplicables simultánea y paralelamente. Así, los Convenios de Ginebra y los convenios de los derechos humanos pueden aplicarse, con frecuencia, de manera cumulativa", Schindler, op. cit., nota 6, p. 9.

10 "Este sistema general, que toma al hombre como sujeto de derechos internacionalmente garantizados, aunque su capacidad procesal sea esencialmente distinta según los diferentes casos y situaciones existentes en el derecho internacional de los derechos humanos strictu sensu, en el derecho internacional humanitario y en el derecho de los refugiados, reposa en principios fundamentales comunes, que informan a las distintas ramas del derecho internacional dirigidas a proteger y garantizar derechos de la persona humana. Podrán haber principios o criterios particulares, de aplicación necesaria sólo en alguna de estas ramas del derecho internacional, como es el caso en especial del derecho humanitario, pero no puede negarse, y sería sumamente grave negar, la existencia de principios comunes y generales a todos ellos, que los vinculan e interrelacionan en base al objetivo esencial de defender y garantizar la dignidad e integridad del ser humano"; Gros Espiell, Héctor, "El derecho internacional de los refugiados y el artículo 22 de la Convención Americana sobre Derechos Humanos", en varios autores, Estudios básicos sobre derechos humanos, Madrid, Civitas, 1988, p. 252. 
Estados que no sean partes en los convenios, dado que expresan las costumbres de los pueblos. ${ }^{11}$

A partir de los Convenios de Ginebra de 1949, se gesta el derecho humanitario actual que luego será ampliado y profundizado en algunos extremos con los protocolos adicionales aprobados en 1977. Los instrumentos internacionales mencionados detallan una serie de medidas a favor de la población civil que no participa en un combate, a la vez que se elabora una distinción entre conflictos armados internacionales y conflictos armados internos, con sus respectivos ámbitos de aplicación normativa.

Sin embargo, a pesar de todo este andamiaje protectivo que se ha diseñado dentro de la comunidad internacional, los flagelos a los niños y niñas como población vulnerable dentro de los conflictos bélicos continúan a la orden del día. Verbigracia, podemos enumerar que alrededor de un tercio de las más de 800 víctimas mortales hasta ahora registradas en el actual conflicto Israel-Líbano, son niños (as) o menores de edad, según informó el director de Programas de Emergencia de UNICEF (Fondo de las Naciones Unidas para la Niñez), Dan Toole. De acuerdo con

11 Pictet, Jean, op. cit., nota 3, p. 71. Para este autor, existen dentro de los principios fundamentales del $\mathrm{DIH}$, el principio de derecho humanitario $-\mathrm{o}$ derecho de los conflictos armados-: "Las partes en conflicto no causarán a su adversario males desproporcionados con respecto al objetivo de la guerra, que es destruir o debilitar el potencial militar del enemigo" (p. 74). El otro principio derivado fundamental, es el principio del derecho de Ginebra: "Las personas puestas fuera de combate y los que no participan directamente en las hostilidades serán respetados, protegidos y tratados con humanidad" (p. 75). Cfr. en un interesante estudio realizado por expertos del Instituto de Estudios Internacionales Thomas J. Watson Jr., de la Universidad de Brown y de la Fundación Arias, allí se habla de la noción de "espacio humanitario" para enmarcar la experiencia humanitaria en la posguerra de Centroamérica: "El concepto de espacio humanitario es un término dinámico. Lejos de ser un sitio cercado de dimensiones permanentes, el espacio humanitario, con la experiencia de la región, sugiere que se extiende o contrae, dependiendo de las circunstancias del contexto. Este espacio puede ser circunscrito - o dilatado- por los mismos actores humanitarios. En resumen, el espacio humanitario no es duradero, ni transferible, sino elástico. En consecuencia, más que llenar el ya existente, las organizaciones y el personal externo pueden, con su propia presencia, ampliar y extender el espacio humanitario. Aún después de marcharse de una escena conflictiva, el espacio que ellos disfrutaron no queda automáticamente disponible para los actores humanitarios que permanecen detrás"; Eguizabal, Cristina et al., Desafios humanitarios en Centroamérica. Lecciones de los conflictos armados recientes, San José, Costa Rica, Fundación Arias para la Paz y el Progreso Humano, 1995, p. 21. 
sus cifras, en los combates realizados en el primer mes de hostilidades habrían muerto al menos 200 niños o jóvenes, mientras que un tercio de los 3,200 heridos serían asimismo menores. Las cifras de UNICEF llegan días después de la masacre de Qana, que dejó 57 civiles muertos, la mayoría de ellos niños. Esta situación tan deplorable se gestó al sur del Líbano y ha sido calificado como el ataque más mortífero realizado a menores, en los primeros veinte días de conflicto. ${ }^{12}$

A continuación pasamos a exponer las principales coordenadas que han motivado la elaboración de este ensayo de fundamentación, cuyo centro fundamental de preocupación consiste en la población de la protección y defensa de la niñez en estado de riesgo social como producto de las guerras, conflictos internos y sus funestas secuelas.

\section{LOS (AS) NIÑOS (AS) COMO SUJETOS SOCIALES, MERECEDORES DE LA TUTELA DE DERECHOS CONNATURALES}

\section{A SU EXISTENCIA}

Antes de emprender un análisis más riguroso de lo concerniente a la práctica internacional de la tutela jurídica de los y las menores en conflictos de guerra, creemos conveniente sustentar a priori una situación relativa al hecho mismo de pertenecer a la niñez. Nos referimos propiamente al derecho a la protección que tienen los niños y niñas a ser respetados en su integridad física y su derecho absoluto a un mejor desarrollo en sus condiciones de vida.

La reacción pública ante los efectos aterradores de la guerra y la violencia sobre la infancia es inmediata, y los estragos menos espectaculares que causan la pobreza, la ignorancia, la falta de higiene y la discriminación pasan muy a menudo inadvertidos sobre esta población infantil. ${ }^{13}$ Nos encontramos entonces que, a partir de lo anterior, un autor como García Méndez aduce que el proceso de construcción de la incapacidad de la infancia se deja explicar con tres hipótesis centrales: a) La historia de la infancia es la historia de su control. Es claro que, según sea el tipo

12 Cable de Agencia Reuters, 30 de julio del 2006, 17:30 h.

13 Valle Iturriaga, José Luis, "Proyección de los derechos humanos en el derecho positivo", en varios autores, Ciclo Académico Conmemorativo del XX Aniversario de la Declaración Universal de los Derechos Humanos, Ilustre Colegio de Abogados de Valencia, 1968, p. 85. 
de infancia de que se trate, diverso será el sujeto activo del control. Para decirlo en términos breves, el estado o los adultos, según sea el caso; b) Tal como lo plantea Philippe Aries en su maravilloso libro ya clásico sobre la historia de la infancia: "Antes del siglo XVII la infancia no existe". Esta afirmación sobre la "inexistencia" de la infancia no significa, obviamente, afirmar que antes del siglo XVII no existían sujetos bajitos de 5, 6 o 7 años. Lo que en realidad Aries quiere decir es que, antes del siglo XVII, estos "sujetos bajitos" no eran considerados como una categoría social diferenciada respecto de los adultos; c) A partir de esta hipótesis de Aries, es posible formular, como sigue, una tercera hipótesis: La infancia va a pagar un precio muy alto por su "descubrimiento". Me refiero a la existencia de un pacto perverso implícito entre esta categoría social recién descubierta y el mundo de los adultos. Reconozco tu existencia, pero por lo que no tienes, por lo que no sabes, por lo que no eres capaz. En otras palabras, el "descubrimiento" de la infancia es el descubrimiento de su incapacidad. ${ }^{14}$

Se ha hablado entonces que la autoproclamada autonomía del derecho de menores es sobre todo y muy especialmente en relación con el derecho constitucional, ${ }^{15}$ pues se ha reconocido que el niño y la niña han de considerarse como parte de un grupo en el cual deben desarrollar la satisfacción de sus necesidades físicas, psíquicas y sociales en el seno de una

14 García Méndez, Emilio, "Niños y adolescentes como sujetos sociales de derechos y deberes", en González Volio, Lorena (ed.), op. cit., nota 8, p. 398. En el artículo 3.1 de la Convención sobre los Derechos del Niño se estipula que: "En todas las medidas concernientes a los niños, que tomen las instituciones públicas o privadas de bienestar social, los tribunales, las autoridades administrativas o los órganos legislativos, una consideración primordial a que se atenderá será el interés superior del niño".

15 "El derecho de menores crea leyes 'protectoras', cuyo contenido esencial consiste en institucionalizar la voluntad omnímoda de un juez que debe actuar como 'buen padre de familia', si el conflicto involucra a un menor, o la voluntad omnímoda de un padre, quien debe actuar con la autoridad y discrecionalidad de un juez, si se trata de un niño o un adolescente... Autónomo del derecho constitucional, el derecho de menores se construye como un derecho que no es ley (en su sentido de voluntad abstracta), de un juez que no es juez, de un proceso que por supuesto no es un proceso y sobre todo de un sujeto, que si algo no es, es ser sujeto. De aquí en adelante nada debe sorprender. Este festival del eufemismo es el resultado de un pacto siempre frágil y provisorio entre el saber (poder) médico y el saber (poder) jurídico", García Méndez, op. cit., nota 14, pp. 400 y 401 . 
familia. ${ }^{16}$ Para un autor como Nikken, el tratamiento especial que debe prevalecer hacia los menores tiene una variable histórica: "la actitud humanitaria hacia el niño, e incluso el reconocimiento de la infancia como una etapa especial de la vida que requiere de un tratamiento distinto al de la edad adulta, se ha conocido en los últimos doscientos años. Anteriormente, las prácticas bárbaras y crueles contra los niños estaban largamente generalizadas en todos los sectores sociales". ${ }^{17}$ En el marco del derecho internacional humanitario, el cuidado de los niños conllevó a que el Comité Internacional de la Cruz Roja en la década de los sesenta - tomando en cuenta nuevas situaciones y métodos de guerra-, enfatizara la inminente necesidad de ampliar y revisar la protección que ofrecía este tipo de derecho a los menores. ${ }^{18}$

Por otra parte, el señor Olara A. Otunnu, representante especial del secretario general de la ONU, encargado de la cuestión de los niños en los conflictos armados, ha externado lo siguiente en torno a la situación de vulnerabilidad de los menores en este tipo de sucesos:

9. Los niños son inocentes y especialmente vulnerables. Están menos preparados para adaptarse o responder al conflicto. Son los menos responsables del conflicto, pero padecen desproporcionadamente sus excesos. Los niños son verdaderamente víctimas sin culpa del conflicto. Además, representan las esperanzas y el futuro de toda sociedad; destruyendo los niños se destruye la sociedad.

10. En el último decenio 2 millones de niños han sido muertos en situaciones de conflicto, más de 1 millón han quedado huérfanos, más de 6 millones han sido gravemente heridos o permanentemente incapacitados y

16 Calvento Solari, Ubaldo, "Protección socio-legal del niño abandonado. Adopción y colocación familiar", Revista Judicial, San José, Costa Rica, año V, núm. 19, mayo de 1981, p. 16.

17 Nikken, Pedro, "Los derechos del niño, de los ancianos y de la mujer: su protección internacional", Revista IIDH, San José, Costa Rica, Instituto Interamericano de Derechos Humanos, julio-diciembre de 1986, p. 26.

18 Para una autora como Sandra Singer, habría que retomar tres aspectos con respecto a la niñez: "Primeramente, como categoría de personas particularmente vulnerables, tienen derecho a una protección especial, pero este principio no estaba explícitamente formulado en ningún artículo. En segundo lugar, estaba la cuestión de su empleo en operaciones militares. Por último, había que estipular alguna disposición teniendo en cuenta su inmadurez, si efectivamente cometen infracciones durante un conflicto armado"; Singer, Sandra, "La protección debida a los niños en situaciones de conflicto armado", Revista Internacional de la Cruz Roja, mayo-junio de 1986, p. 11. 
más de 10 millones han quedado marcados por graves traumas psíquicos. Muchos niños, y especialmente muchas mujeres jóvenes, han sido objeto de violaciones y otras formas de violencia sexual como instrumento de guerra deliberado.

11. Actualmente hay más de 20 millones de niños que han sido desplazados por la guerra dentro y fuera de sus países. Unos 300.000 menores de 18 años son explotados como niños soldados en todo el mundo. Y cada mes unos 800 niños son muertos o mutilados por minas terrestres. ${ }^{19}$

La necesidad de que el derecho internacional humanitario tutele el interés de los (as) niños (as) sometidos a diferentes conflictos que puedan representar un peligro para sus vidas e integridad, será revisado en las páginas siguientes. Con ello determinaremos si los menores son realmente "sujetos sociales" o no, en el sentido que existan mecanismos para hacer más justiciables sus derechos en coyunturas tan desdeñables como son las provocadas por las guerras y otros acontecimientos bélicos.

\section{LA TUTELA DE LA NIÑEZ EN EL DIH. APLICACIÓN Y VIGENCIA DE INSTRUMENTOS INTERNACIONALES}

El interés del DIH por proteger a los niños y niñas durante los conflictos armados, se remonta a los albores de la Primera Guerra Mundial. Finalizada esta confrontación, la organización británica Save the Children y su homóloga sueca Rädda Barnen elaboraron el proyecto de una Declaración de los Derechos del Niño, que la Sociedad de Naciones aprobó en 1924. La Declaración de Ginebra — o también conocida como la Declaración de la Unión Internacional para la Protección a la Infancia - ofrecía protección y asistencia especial a los niños sin distinción de raza o nacionalidad. Es ese el punto de partida del desarrollo internacional de la protección de los derechos de la niñez; allí se especificaba la necesidad de que la niñez debería de ser el primer grupo social que recibiera atención y protección en caso de desastre o catástrofe.

Tras la Segunda Guerra Mundial se revivió esta declaración, y en 1959, las Naciones Unidas, ampliando la declaración anterior, aprobaron

19 Organización de las Naciones Unidas, Documento A/54/430, versión español (original inglés), 1o. de octubre de 1999, p. 6. 
la Declaración de Derechos del Niño (CIDN). ${ }^{20}$ En esta coyuntura de posguerra, los conflictos de liberación y los combates irregulares hacían difícil distinguir al soldado civil, además que el armamento era más rápido y fulminante, por lo que "los niños son una categoría de víctimas de las más vulnerables en una situación de conflicto armado o de sus consecuencias... Gran parte de este interés se debe a los programas realizados por los medios de comunicación y el consiguiente interés del público por los acontecimientos en el sudeste asiático como en Kampuchea y la frontera con Tailandia". ${ }^{21}$

Es necesario partir, como tesis de principio, que la protección de los niños y niñas en el caso de conflictos internacionales, debe verse como la necesaria protección a sectores y grupos vulnerables, que ha sido una preocupación desde tiempos de lejana data, por parte del DIH. Repasando muy brevemente qué entienden las normas principales del DIH, en relación a todas aquellas personas que no participan en un conflicto armado y que son proclives a los peligros y vicisitudes de esta actividad bélica, debemos decir inicialmente que el número de víctimas civiles - es decir las personas que no se prestarían a los combates durante la Segunda Guerra Mundial - hicieron necesario el establecimiento de un régimen especial de derecho humanitario para esta categoría de víctimas de los conflictos armados internacionales. Esta pretensión se materializó en el Cuarto Convenio de Ginebra de 1949.22

Posteriormente en los Convenios de Ginebra, en 1957 una comisión de expertos redactó un Proyecto de Normas en la XIX Conferencia Internacional de la Cruz Roja, para tratar sobre el tema de la protección a la población civil en el marco de un conflicto armado. Sin embargo, las potencias no manifestaron ningún interés de comprometerse sobre esta base. Más este antecedente no desalentó al CICR y valiéndose de un estímulo coyuntural por parte de la XX Conferencia de la Cruz Roja en 1965 y de la Asamblea General de las Naciones Unidas en 1968, se elaboró un

20 Véase sobre este convenio infra epígrafe III, 2, A.

21 Singer, op. cit., nota 18, p. 4.

22 Swinarski, op. cit., nota 3, p. 34. Véase sobre el estatuto y trato de las personas protegidas, el artículo 27 del IV convenio y el artículo 75 del Protocolo II. Sin embargo, consideramos que el Protocolo I es el que define más concretamente lo que debe entenderse como "personas civiles" y "población civil", en su artículo 50; también, el artículo 52 establece las reglas de protección a los "bienes de carácter civil"; $c f r$. artículo 13, párr. 2 del Protocolo II. 
conjunto de disposiciones que finalmente fueron incorporadas con algunas modificaciones en los protocolos adicionales a los Convenios de Ginebra, y que sirvieron de base además a la Conferencia Diplomática de 1974-1977. ${ }^{23}$

Esta preocupación por la protección eficaz a la población civil ha venido necesitando una respuesta más efectiva, en razón de que la situación ha empeorado considerablemente en los conflictos armados del siglo $\mathrm{XX}$, sean internos o internacionales. A manera de ejemplo, puede decirse que en la Primera Guerra Mundial alrededor del 5\% de las víctimas eran civiles; en la Segunda Guerra Mundial el número de víctimas aumentó al 48\%; en el caso de conflictos como el del Líbano, las estadísticas hablan de que 80 o $90 \%$ de las víctimas han sido civiles y básicamente mujeres y niños; en la guerra de la antigua Yugoslavia el porcentaje que se señala es de que $90 \%$ o más de las víctimas han sido civiles y, de nuevo, mujeres y niños abrumadoramente. ${ }^{24}$ Procedemos seguidamente a adentrarnos en aquellas provisiones establecidas en diferentes ámbitos normativos, que tienen la finalidad de mostrarnos la tutela de la niñez en casos de guerra o conmoción interna.

\section{Las normas del DIH de protección a la niñez previstas en los Convenios de Ginebra y sus protocolos adicionales}

El principal propósito de las convenciones suscritas en Ginebra a finales de la década de los cuarenta, fue el de articular reglas humanitarias aplicables a los conflictos de orden internacional. ${ }^{25}$ Por lo tanto, la necesidad de asistir a las víctimas producidas por las guerras, tanto de los combatientes como los que no lo eran, inspira a que la comunidad internacional tome un papel más activo en este asunto de los combatientes.

23 Pictet, Jean, op. cit., nota 3, p. 63. El autor mencionado continúa: "De este impresionante conjunto mencionaremos, en primer lugar, una certera definición de la población civil y de sus bienes, por oposición a los militares y a los objetivos militares, que son los únicos que pueden ser atacados. Después se confinó expresamente que de la inmunidad general se benefició la población civil. Se puntualizó que ésta no debe ser atacada como tal, y que se prohíben los bombardeos llamados de atemorización, como los bombardeos sin discriminación o como represalia"; id., op. cit., en esta misma nota.

24 Odio Benito, Elizabeth, op. cit., nota 8, p. 270.

25 Buergenthal, International..., cit., nota 7, p. 251. 
Los Convenios de Ginebra fueron concluidos en 1949 y entraron en vigencia en 1950. Ellos son a) Convenio de Ginebra para aliviar la suerte de los heridos y enfermos de las fuerzas armadas en campaña (I, CG); b) Convenio de Ginebra para aliviar la suerte de los Heridos, Enfermos y Náufragos de las Fuerzas Armadas en el Mar (II, CG): c) Convenio de Ginebra sobre el Trato de los Prisioneros de Guerra (III, CG); y d) Convenio de Ginebra sobre la Protección de Personas Civiles en Tiempo de Guerra (IV, CG). Los convenios y los protocolos de Ginebra regulan muy concretamente las diferentes provisiones en torno a los derechos de la niñez en general que participa tanto en el marco de un conflicto armado internacional como en un conflicto de naturaleza endógena, que cumpla con los requisitos estipulados por los instrumentos del caso.

De todos los Convenios de Ginebra citados, nos interesa adentrarnos en el IV, debido a que se estipulan una serie de atenciones especiales que deben recibir los niños y niñas, tomando en cuenta sus particulares necesidades. Tenemos provisiones tales como que las altas partes contratantes deben autorizar el libre paso de socorros para niños menores de quince años y para mujeres encintas (artículo 23). La potencia ocupante debe facilitar el buen funcionamiento de las instituciones dedicadas a la asistencia en favor de los niños en un territorio ocupado, a la vez que está prohibido que la potencia ocupante haga modificaciones por lo que respecta a la familia o al estatuto personal de los niños (artículo 50). Cabe mencionar, asimismo, el artículo 51 del IV Convenio de Ginebra, en el que se prohíbe que una potencia ocupante obligue a trabajar a personas protegidas menores de 18 años. Las partes en un conflicto están obligadas a proveer la manutención de las personas que dependan de los internados, si carecen de medios suficientes de subsistencia o no pueden ganarse la vida por sí mismas (artículo 81). En el artículo 82 del IV Convenio de Ginebra se estipula que, siempre que sea posible, los miembros internados de una misma familia deberán estar reunidos en los mismos locales y alojados aparte de los demás internados, además de concedérseles las facilidades necesarias para hacer vida familiar. Los internados podrán solicitar que los hijos que hayan permanecido en libertad sin vigilancia de los padres sean internados con éstos (artículo 82). Las mujeres encintas y parturientas, así como los niños menores de quince años, que las partes en conflicto hayan internado por razones de seguridad, recibirán suplementos nutritivos adecuados a sus necesidades fisiológicas (artículo 89). 
En el marco de un encuentro con especialistas en la materia de DIH, se ha dicho que la protección específica a la niñez que se deriva del IV Convenio de Ginebra de 1949, consiste en la obligación de brindar un respeto y una protección especiales contra cualquier forma de abuso, sin olvidar la obligación de evacuar a los niños en caso de necesidad, cuidarlos y prestarles asistencia, reunirlos con sus familiares cuando se encuentren separados de ellos, velar por su educación, preservar su entorno cultural, dar un trato particular a los niños detenidos y no dictar penas de muerte contra menores de 18 años. ${ }^{26}$

Con el paso del tiempo, se hizo necesario adicionar otra serie de provisiones legales al DIH, ya sea para complementar las existentes o establecer nuevos alcances en este campo. Es así como aparece la figura de los protocolos, con la intención de precisar y ahondar sobre distintos tópicos establecidos en los convenios de 1949. De 1974 a 1977, se celebró una conferencia diplomática cuya finalidad era complementar y desarrollar el derecho internacional humanitario, habida cuenta de su evolución. Al término de la conferencia se aprobaron, en 1977, los dos protocolos adicionales a los Convenios de Ginebra. Estos instrumentos mejoran considerablemente la protección en favor de la población civil y, por consiguiente, de los niños. Con las nuevas disposiciones, tanto del Protocolo I como del Protocolo II, se reafirman y desarrollan las del IV Convenio de Ginebra. $^{27}$

E1 Protocolo I (en adelante PI), se denomina como "Protocolo I Adicional a los Convenios de Ginebra del 12 de agosto de 1949, relativo a la protección de las víctimas de los conflictos armados internacionales". Se ha dicho que su denominación "es un tanto confusa, porque el protocolo no sólo se aplica a conflictos armados internacionales, cubiertos por el artículo 2 común a los Convenios de Ginebra (y definidos como conflictos entre dos o más Estados partes del tratado), sino que el artículo 1 (4) del protocolo también determina su aplicación a otra serie de conflictos". ${ }^{28}$

26 CICR-Organización de Estados Americanos, "Mesa redonda II, Protección de las niñas y los niños en las situaciones de violencia", Conferencia de Expertos Gubernamentales, San José, Costa Rica, del 6 al 8 de marzo del 2001, CICR, 2002, p. 77.

27 Plattner, Denise, "La protección a los niños en el derecho internacional humanitario", Revista Internacional de la Cruz Roja, Ginebra, Suiza, núm. 63, mayo-junio de 1984, p. 148.

28 Buergenthal et al., Manual..., cit., nota 2, pp. 133 y 134. 
En el marco de la coyuntura de aspiraciones de reivindicación anticolonialista que permeaban en diferentes lugares de los continentes africanos y asiáticos, este artículo 1 (4) del protocolo fue visto con reticencia por parte de algunos países. Consideraban que en razón que el artículo 3 a) del PI hacía aplicables los cuatro convenios a los conflictos que cubre y por ende, las guerras de liberación nacional pasaban a incluirse dentro de las situaciones fácticas que cubren los convenios de Ginebra. ${ }^{29}$ Por otra parte, este protocolo en su artículo 75 contienen la innovación de enumerar los derechos fundamentales de "las personas que estén en poder de una parte en conflicto", reafirmando y ampliando las garantías contenidas en el artículo 3 común a los cuatro convenios.

Con relación al Protocolo II (PII en adelante), denominado "Protocolo Adicional a los Convenios de Ginebra del 12 de agosto de 1949, relativo a la protección de las víctimas de los conflictos armados sin carácter internacional", el mismo es aplicable a los conflictos armados sin carácter internacional, pues éstos deben ser de mayor intensidad y no se aplica a las situaciones de "tensiones internas y disturbios interiores". ${ }^{30}$ El PII es un producto del artículo 3 común a los cuatro convenios de Ginebra de 1949 y se aplica a los conflictos armados no cubiertos en el primer artículo del PI, "que se desarrollen en el territorio de una alta parte contratante entre sus fuerzas armadas y fuerzas armadas disidentes o grupos armados organizados que, bajo la dirección de un mando responsable, ejerzan sobre una parte de dicho territorio un control total que les permita realizar operaciones sostenidas y concertadas y aplicar el... protoco1o". ${ }^{31}$ Resulta necesario entonces, con la finalidad de precisar aun más los alcances aplicativos del DIH, distinguir entre conflictos armados internacionales y aquellos que no lo son, pero que igualmente revisten suma importancia al existir disposiciones legales de ejecución inmediata.

Si damos una mirada a lo dispuesto en los citados protocolos, respecto de la niñez como preocupación central de este ensayo, nos va-

29 Ibidem, p. 134.

30 Protocolo II Adicional a los Convenios de Ginebra, artículo 1, párrafo 2. "Por consiguiente el Protocolo II sólo se aplicará a conflictos de gran intensidad, pero sin que se trate forzosamente de una guerra civil caracterizada, pues aquí no se exige el reconocimiento de beligerancia ni la existencia de un poder cuasigubernamental en la parte sublevada. Para éstos, el artículo 3 de 1949 sigue estando en vigor y se invoca en conflictos no cubiertos por el Protocolo II", Pictet, Jean, op. cit., nota 3, p. 58.

31 Protocolo II Adicional a los Convenios de Ginebra, artículo 1, párrafo 1. 
mos a encontrar con la aparición del principio de protección especial para este sector tan vulnerable y que se encuentra inserto en el artículo 77 del PI, que reza lo siguiente: "Los niños serán objeto de un respeto especial y se les protegerá contra cualquier forma de atentado al pudor. Las partes en conflicto les proporcionarán los cuidados y la ayuda que necesiten, por su edad o por cualquier otra razón". ${ }^{32}$

Hemos elaborado una clasificación de los derechos y deberes en favor de la niñez que se encuentran dentro de la normativa del DIH, en aras de sistematizar una exposición de los mismos. A continuación la detallamos y exponemos en cuatro grandes apartados: ${ }^{33}$

a) Derechos de los (as) niños (as) en su ámbito familiar que deben ser respetados en tiempo de guerra.

- Derechos de los niños huérfanos o separados de su madre (artículo $24 \mathrm{IV}, \mathrm{CG})$.

- Derechos de los niños recién nacidos (artículo 8, PI).

- Reunión de familiares dispersos (artículos 26 y 82, IV, CG; artículo 74, PI; párrafo 3, artículo 4, PII).

- Potestad de recibir comunicaciones entre los miembros de la familia (artículo 25, IV, CG).

b) Identificación de los niños (as) durante los conflictos armados.

- Constitución de oficinas y agencia central de informaciones para tramitar informaciones con datos relativos a las personas protegidas (artículo 136, IV, CG).

- Las partes tomarán las medidas necesarias para facilitar la identificación de los niños y registrar su filiación (artículo 50, IV, CG; artículo 24, IV, CG; párrafo 3 artículo 78, PI).

c) Derechos de los niños (as) inherentes a su condición que deben ser respetados en los conflictos armados.

32 Este principio se aplica también en caso de conflictos armados internacionales, según se desprende del párr. 3, artículo 4 del PII.

33 Hemos realizado esta clasificación, tomando en cuenta tres distinciones elaboradas por De Praux, Singer y el impreso de la Cruz Roja Internacional denominado Protección Jurídica de los Niños en los Conflictos Armados. 
- Derecho a la asistencia médica (párrafo 1, artículo 8 del PI).

- Derecho a la protección de la educación, la cultura y las tradiciones (artículos 24, 50 y 94, CG; inciso a), párrafo 3, artículo 4, PII).

- Protección a la nacionalidad del niño (artículo 50, IV, CG).

- Derecho a la alimentación de los menores (artículo 8, IV, CG).

d) Derechos de los niños (as) contra los efectos de las hostilidades.

- Detención e internamiento de los niños (arts. 76, 82 y 89, IV, CG).

- Potestad de liberación de los niños de corta edad (art. 132, IV, CG).

- No puede dictarse pena de muerte contra una persona protegida que no sea menor de dieciocho años (artículo 68, IV, CG; párrafo 5 artículo 77, PI; párrafo 4 artículo 6, PII).

- Prohibición de reclutar niños menores de quince años (letra c), párrafo 3, artículo 4, PII).

- Los niños combatientes menores de quince años tienen un trato preferencial (párrafo 3, artículo 77, PI y letra d) párrafo 3 artículo 4, PII).

- Derecho que tienen los niños a evacuar en primer lugar una zona de conflicto (artículo 77 IV, CG).

- Creación de zonas de seguridad para atender a los niños (artículo 14, IV, CG).

- Prioridad de envío de aditamentos para el socorro de los niños (artículo 23, IV, CG).

2. Las iniciativas de protección a la niñez previstas en instrumentos internacionales y otros acuerdos generados en el sistema de Naciones Unidas

La comunidad internacional adoptó diferente normativa a través de pactos internacionales, que aseguran el deber de los Estados de instaurar medidas especiales de protección y asistencia en favor de todos los niños y adolescentes, sin discriminación alguna. Esta situación se ve reflejada en los artículos 10.3 del Pacto Internacional de Derechos Económicos, Sociales y Culturales (PIDESC) y 24.1 del Pacto Internacional de Derechos Civiles y Políticos (PIDCP), ambos instrumentos adoptados en 1966 por la Asamblea General de la ONU. 
De igual manera, en varios instrumentos internacionales relativos a los derechos humanos, se han incorporado algunos elementos de los derechos de la niñez, indicando la necesidad de una protección especial. Entre ellos podemos mencionar no sólo los analizados anteriormente - sean los pactos internacionales sobre los derechos humanos y las Convenciones de Ginebra de 1949 sobre el derecho internacional humanitario- , sino que además una convención de la Organización Internacional del Trabajo (OIT). ${ }^{34}$ Vamos a hacer mención seguidamente de algunos acontecimientos que desde nuestra óptica, coadyuvaron al enriquecimiento y avance de la codificación internacional de la protección con la que deben contar los menores en caso de conflictos armados.

\section{A. La Declaración de Derechos del Niño (1959)}

Ya hemos hecho una breve mención de esta declaración en este trabajo, ${ }^{35}$ por lo que debemos decir que este instrumento se adopta por la Asamblea General de la ONU, el 20 de noviembre de 1959. Se considera que la CIDN es el instrumento que aborda con más profundidad los derechos de la infancia, puesto que es muy avanzado para su época, y de hecho sirvió de inspiración para la formulación de la posterior Convención sobre los Derechos del Niño. En torno a la discriminación, se aduce que los Estados parte de la CIDN "tomarán todas las medidas apropiadas para garantizar que el niño se vea protegido contra toda forma de discriminación o castigo por causa de la condición, las actividades, las opiniones expresadas o las creencias de sus padres, o sus tutores o de sus familiares" (artículo 2.2). Entre los derechos fundamentales reconocidos en la convención, se dispone la prohibición de que el niño sea objeto de injerencias arbitrarias o ilegales en su vida privada, su familia, su domicilio, o su correspondencia, ni de ataques ilegales a su honra y a su reputación" (artículo 16.1). ${ }^{36}$ Se trata, con esta novedosa declaración, de ir perfilando

34 En el Convenio núm. 182 de la Organización Internacional del Trabajo, Sobre la Prohibición de las Peores Formas de Trabajo Infantil, adoptado en 1999, se prohíbe el reclutamiento forzoso u obligatorio de niños menores de 18 años para utilizarlos en conflictos armados.

35 Véase supra epígrafe III, pp. 74-75.

36 La Declaración Americana de los Derechos y Deberes del Hombre estipula en su artículo XVII que: "Toda persona tiene derecho a que se le reconozca en cualquier parte 
y conformando un sustrato protectivo que resguarde los derechos de la población menor en un ámbito integral y bastante amplio.

\section{B. Declaración sobre la Protección de la Mujer y el Niño en Estados de Emergencia o de Conflicto Armado (1974)}

En 1974, la Asamblea General de la ONU aprobó la Declaración sobre la Protección de la Mujer y el Niño en Estados de Emergencia o de Conflicto Armado, en la que se condenan los ataques y los bombardeos contra la población civil, se prohíben la persecución, la reclusión, la tortura y todas las formas de violencia degradante contra las mujeres y niños. ${ }^{37}$ Otra iniciativa a manera de ejemplo, es el Grupo de Trabajo de Formas Contemporáneas de Servidumbre, establecido en 1975, que ha tratado con los asuntos de prostitución infantil, trabajo infantil, y adopciones de menores entre Estados. ${ }^{38}$

El anterior desarrollo internacional motivó al Estado de Polonia a presentar en 1978 la propuesta a la ONU en el sentido de que la niñez necesita de un cuerpo coherente de normas jurídicas para la protección de sus derechos específicos, lo que significó la primera idea sobre la necesidad de una convención. Un año después, en 1979 la Comisión de los Derechos Humanos de la ONU creó al Grupo de Trabajo Abierto para la Cuestión de una Convención sobre los Derechos del Niño, con la finalidad de revisar el documento propuesto presentado por Polonia y estudiar la posibilidad real de aprobar una convención en ese sentido. El grupo de

como sujeto de derechos y obligaciones, y a gozar de los derechos fundamentales" (las cursivas son mías).

37 Singer, Sandra, op. cit., nota 18, p. 10. La anterior declaración fue aprobada por la Asamblea General en su resolución 3318 (XXIX), de 14 de diciembre de 1974, que a su vez tuvo que examinar la recomendación del Consejo Económico y Social contenida en su resolución 1861 (LVI) de 16 de mayo de 1974. Otros importantes antecedentes sobre la materia, dignos de ser nombrados son los siguientes: las resoluciones 2444 (XXIII) de 19 de diciembre de 1968, 2597 (XXIV) de 16 de diciembre de 1969, y 2674 (XXV) y 2675 (XXV) de 9 de diciembre de 1970, relativas al respeto de los derechos humanos y a los principios básicos para la protección de las poblaciones civiles en los conflictos armados, así como la resolución 1515 (XLVIII) del Consejo Económico y Social, de 28 de mayo de 1970, en la que el consejo pidió a la Asamblea General que examinara la posibilidad de redactar una declaración sobre la protección de la mujer y el niño en estados de emergencia o de guerra.

38 Fox, Stanford J., "Beyond the American Legal System for the Protection of Children's Rights", Family Law Quarterly, verano de 1997, p. 34. 
trabajo comprendió a 43 representantes de los Estados miembros de la comisión; también se incorporaron otros delegados por parte de organismos intergubernamentales tales como UNICEF, OIT, ACNUR y las organizaciones no gubernamentales con estatuto constitutivo ante el Consejo Económico de la ONU (ECOSOC). Después de largas discusiones y revisiones, la Comisión de Derechos Humanos de la ONU aprobó el texto definitivo de la convención, el 8 de marzo de 1989, y lo envió al ECOSOC, desde donde emprendió su viaje definitivo a la Asamblea General de la ONU. ${ }^{39}$

\section{La Convención de Derechos del Niño (1989)}

Aunado a lo expuesto en líneas precedentes, la gestación de la Convención de Derechos del Niño, tiene como base las resoluciones 33/166, de 20 de diciembre de 1978, y 43/112, de 8 de diciembre de 1988, todas de la Asamblea General. Asimismo, fueron claves en todo este proceso la resolución 1989/57, de 8 de marzo de 1989 de la Comisión de Derechos Humanos, por lo que la comisión decidió transmitir a la Asamblea General, por conducto del Consejo Económico y Social, el proyecto de convención sobre los derechos del niño y la resolución de 1989/79 del Consejo Económico y Social, de 24 de mayo de 1989. Finalmente la convención fue adoptada y abierta a la firma y ratificación por la Asamblea General en su resolución 44/25, de 20 de noviembre de 1989, entrando en vigor en menos de un año —el 2 de septiembre de 1990-, de conformidad con el artículo 49, que exige para el vigor de este tratado al menos veinte ratificaciones o adhesiones.

Por primera vez en la historia del derecho internacional, los derechos de la niñez son incorporados en un tratado que tendrá fuerza coercitiva para todos aquellos Estados que los ratifiquen, a diferencia de la Declaración de 1959, que se quedaba en tan sólo una carta de buenas intenciones. Al mismo tiempo, sus normas engrosarían progresivamente el derecho consuetudinario de los derechos de la niñez. Con la Convención sobre los Derechos del Niño se abandonó la antigua doctrina de la situa-

39 Sagastume Gemmell, Marco Antonio, La Protección Internacional de los Derechos de la Niñez, Unión Europea, Guatemala, Consejo Superior Universitario de Centroamérica-CSUCA, 2002, pp. 15 y 16. 
ción irregular ${ }^{40}$ que consideraba a los niños incapaces de asumir responsabilidad por sus acciones. Esta convención, junto con otros instrumentos internacionales, acogió la doctrina de la protección integral, que reconoce al niño su condición de sujeto de derecho y le confiere un papel principal en la construcción de su propio destino. En materia penal, específicamente, significó el cambio de una jurisdicción tutelar a una punitivo-garantista, en la cual, entre otras medidas, se reconocen plenamente los derechos y garantías de los niños; se les considera responsables de sus actos delictivos; se limita la intervención de la justicia penal al mínimo indispensable; se amplía la gama de sanciones, basadas en principios educativos; y se reduce al máximo la aplicación de las penas privativas de la libertad.

La Convención sobre los Derechos del Niño, entre otros instrumentos internacionales, y la elaboración de la doctrina de la protección integral trajeron consigo el surgimiento del derecho de los niños como una nueva rama jurídica, basada en tres pilares fundamentales: el interés superior del niño, entendido como la premisa bajo la cual se debe interpretar, integrar y aplicar la normativa de la niñez y la adolescencia, y que constituye, por ello, un límite a la discrecionalidad de las autoridades en la adopción de decisiones relacionadas con los niños; el menor de edad como sujeto de derecho, de manera que se reconocen a éste tanto los derechos humanos básicos como los que sean propios de su condición de niño; y el ejercicio de los derechos fundamentales y su vínculo a la autoridad parental: siendo que la autoridad parental tiene como único fin procurar al niño la protección y los cuidados indispensables para garantizar su desarrollo integral, constituye una responsabilidad y un derecho para los padres, pero también un derecho fundamental para los niños a ser protegidos y orientados hasta alcanzar su plena autonomía. Por ello, el ejercicio de autoridad debe disminuir conforme avanza la edad del niño.

La citada convención también se aplica a los niños y a las niñas en situación de conflictos armados, ya sea de carácter internacional o interno, y también a los niños y niñas refugiados (artículo 22), a la vez que en su artículo 38 amplía a los conflictos armados no internacionales el ám- 
bito de aplicación de las normas del artículo 77 del PI. ${ }^{41}$ Precisamente en torno al artículo 38 de la convención que nos ocupa, tenemos que esta norma está compuesta por cuatro párrafos que enuncian de manera directa la situación a seguir en el caso de los conflictos armados y su incidencia en los menores. En primer lugar, los Estados parte se comprometen a respetar las normas del derecho internacional humanitario. Segundo, se prohíbe que un menor de 15 años participe directamente en las hostilidades; también prohíbe el reclutamiento de menores de 15 años en las fuerzas armadas. Cabe destacar que el secretario general de la Organización de las Naciones Unidas, en el marco de la primera consulta regional sobre las repercusiones de los conflictos armados en los niños en la región de los países árabes, celebrada en Egipto, ${ }^{42}$ manifiesta entre sus recomendaciones relativas a este punto la necesidad de enmendar el artículo 38 de la Convención sobre los Derechos del Niño para elevar la edad de reclutamiento en las fuerzas armadas de 15 a 18 años; ejercer presión sobre los gobiernos para que no recluten o acepten a niños en sus fuerzas armadas; promover un conjunto de posibles medidas e incentivos favorables y apropiados, especialmente en materia de enseñanza y empleo, para desalentar el reclutamiento de niños y aumentar la capacidad y mejorar los métodos para su desmovilización con el fin de evitar que la tendencia de los soldados a recurrir a la violencia pase a la sociedad civil después de terminada la guerra. ${ }^{43}$ Tercero, los Estados parte deberán adoptar todas las medidas posibles para asegurar la protección y el cuidado de los niños y niñas afectados por un conflicto armado.

El tratado presenta la particularidad de que con la finalidad de examinar los progresos realizados en el cumplimiento de las obligaciones contraídas por los Estados parte, se delegará al Comité de los Derechos del Niño. Este comité estará integrado por diez expertos de gran integridad moral y reconocida competencia de los derechos de la niñez. El informe sobre las medidas que hayan adoptado para dar efecto a los dere-

41 Se prohíbe la participación directa en las hostilidades de los niños de menos de 15 años (párrafo 2) y su reclutamiento en las fuerzas armadas, y se alienta a que entre los niños de 15 a 18 años se aliste en primer lugar a los de más edad (párrafo 3).

42 Véase infra pp. 89 y 90.

43 Organización de las Naciones Unidas, Promoción y Protección de los Derechos del Niño: Repercusiones de los Conflictos Armados sobre los Niños, Quincuagésimo primer periodo de sesiones, Tema 108 del programa provisional, Documento A/51/306/Add.1, versión español (original inglés), 9 de septiembre de 1996, p. 13. 
chos reconocidos en la convención y sobre el progreso en cuanto al goce de esos derechos, debe ser presentado a los dos años a partir de la fecha en la que para cada Estado parte haya entrado en vigor la convención. Posteriormente se presentará cada cinco años. En estos informes se deberá indicar las circunstancias y dificultades, si las hubiere, que afecten el cumplimiento de las obligaciones derivadas de la convención. Deberá contener toda la información suficiente para que el comité tenga cabal comprensión en el país de que se trate. Este comité informará cada dos años de la Asamblea General de la ONU sobre sus actividades y podrá pedir a los Estados parte más información relativa a la aplicación de la convención.

\section{Protocolo Facultativo a la Convención de Derechos del Niño (2000)}

El 25 de mayo del 2000 se aprueba el Protocolo Facultativo 2000 de la anterior Convención de Derechos del Niño, y entre sus disposiciones más relevantes, tenemos la de prohibición de reclutar menores de dieciocho años tanto dentro de las fuerzas armadas (artículos 1 y 2), así como en los grupos armados insurgentes (artículo 4). Sobre dicho protocolo y la situación de la niñez en conflictos armados, tenemos la opinión del Centro por la Justicia y el Derecho Internacional (CEJIL) vertida en el marco de la audiencia prevista por la Corte Interamericana de Derechos Humanos, con la finalidad de dictar la Opinión Consultiva núm. OC-17/2002 (“Condición Jurídica y Derechos Humanos del Niño"):

Este tipo de conflictos han ido aparejados de violaciones a los derechos humanos y al derecho internacional humanitario en perjuicio de niños y adolescentes de la región, con consecuencias para ellos que resultan aún más intensas y traumáticas que para los adultos... Además, los niños deben enfrentarse muchas veces al desplazamiento y separación de sus familias, privándolos de un entorno seguro.

Al respecto, es importante la existencia del Protocolo Facultativo de la Convención sobre los Derechos del Niño relativo a la participación de los niños en conflictos armados como una forma de complementar las obligaciones mínimas de los Estados establecidas en la convención sobre los Derechos del Niño en relación con los niños en conflictos armados y su recuperación, pues, entre otras cosas, se eleva la edad mínima para el reclutamiento de 15 a 18 años. 
Asimismo, no obstante que muchos Estados reconocen la existencia de niños soldados reclutados por las fuerzas armadas y que adquieren el compromiso de dictar disposiciones para evitar nuevos reclutamientos, por lo general sucede que no han elaborado disposiciones para facilitar la desmovilización de los niños actualmente reclutados, impidiéndoles a estos últimos el acceso a la educación, la reunificación familiar o la alimentación y albergue necesarios para su reintegración social. ${ }^{44}$

No cabe la menor duda que constituye un debate central la utilización de los menores como protagonistas y actores en el campo de batalla, cuando se está en presencia de un conflicto bélico. Se estima en general que cerca de 300,000 niños menores de 18 años han sido obligados o inducidos a tomar armas como niños soldados. Todos los años, entre 8,000 y 10,000 niños caen víctimas de las minas terrestres. El Foro Mundial de la Educación celebrado en abril de 2000 reconoció que el número y el alcance de los conflictos ocurridos en el último decenio habían sido importantes obstáculos en el logro del objetivo de proporcionar una educación para todos en 2000. Los datos del UNICEF indican que, durante el decenio comprendido entre 1986 y 1996, 2 millones de niños murieron, 6 millones fueron lesionados, más de 10 millones fueron traumatizados y más de 1 millón quedaron huérfanos como consecuencia de conflictos armados. ${ }^{45}$

Los niños y niñas afrontan situaciones de vulnerabilidad al participar en la guerra, debido entre otras cosas, a que suelen ser pobres, analfabetos y de zonas rurales. Los voluntarios suelen verse motivados por el deseo de escapar a la pobreza o son fácilmente seducidos por llamamientos a ideologías étnicas, religiosas o políticas. Los adolescentes cuya identidad está formándose son particularmente vulnerables a los señuelos del

44 Corte IDH, Condición Jurídica y Derechos Humanos del Niño. Opinión Consultiva OC-17/02 del 28 de agosto de 2002. Serie A, núm. 17, p. 37. Sobre el punto de atender la problemática de los niños soldados, y la necesidad de elevar la edad de reclutamiento, ya se había pronunciado en este sentido el relator especial de la ONU, mucho antes de la entrada en vigencia del protocolo (véase Organización de las Naciones Unidas, Documento A/54/430..., cit., nota 19, párr. 45).

45 Organización de las Naciones Unidas, Consejo de Seguridad, Informe del Secretario General, Asamblea General, Quincuagésimo quinto periodo de sesiones, Consejo de Seguridad, Quincuagésimo quinto año, Tema 112 del programa provisional "Promoción y protección de los derechos del niño: los niños y los conflictos armados", Documento A/55/163-S/2000/712, versión español, 19 de julio de 2000, p. 2. 
combate. Los que sobreviven quedan con frecuencia heridos física y psicológicamente, tras haber perdido años de escolarización y socialización.

En virtud de lo anteriormente expuesto y a grosso modo, podemos establecer que el protocolo en mención fortalece la convención de varias maneras importantes: a) Establece que la edad mínima para el reclutamiento obligatorio o la participación directa en hostilidades será de 18 años, con lo que subsana lo dispuesto en los párrafos segundo y tercero del artículo 38 de la Convención de Derechos del Niño; b) Exhorta a los Estados parte a elevar la edad mínima para el reclutamiento voluntario y a proporcionar protección y salvaguardias especiales a los menores de 18 años; c) Prohíbe categóricamente que los grupos armados recluten a menores de 18 años o los utilicen en hostilidades; $d$ ) Insta a los Estados parte a que presten cooperación técnica y asistencia financiera para ayudar en la prevención del reclutamiento y el despliegue de niños, y para mejorar la rehabilitación y reintegración social de los ex niños soldados.

\section{E. Otras iniciativas gestadas en el sistema universal}

Aparte de lo anteriormente expuesto, hemos encontrado un par de situaciones en las que la Organización de las Naciones Unidas ha encaminado acciones tendentes a mitigar el flagelo del ataque y peligro a los niños y niñas en situación de conflicto. Es así como podemos hablar inicialmente de la Resolución 1261 aprobada por el Consejo de Seguridad de la organización, en 1999. Para el 12 de febrero de 1999, se invitó al representante especial, junto al presidente del Comité Internacional de la Cruz Roja (CICR) y al director ejecutivo del UNICEF, a dirigirse al Consejo de Seguridad en un debate abierto sobre la cuestión de la protección de los civiles en los conflictos armados. Posteriormente, la Oficina del representante especial, en estrecha colaboración con el UNICEF, participó activamente en la preparación del informe del secretario general sobre ese tema (S/1999/957), para conseguir que figurasen en él todas las cuestiones relativas a los niños. El 16 y el 17 de septiembre el consejo examinó el informe del secretario general y luego aprobó la resolución 1265 (1999).

En la citada resolución, se incluye una serie de cuestiones que han sido elementos fundamentales de la labor de promoción de los intereses de los niños llevada a cabo por el representante especial. En la resolución se condena la elección de niños como blanco en conflictos armados; se 
reconoce que hay que tener en cuenta la protección y el bienestar de los niños en las negociaciones de paz; se insta a las partes en conflicto a que adopten medidas para proteger a los niños; se exhorta a que se ponga fin al reclutamiento y la utilización de niños en los conflictos armados; y se insta a la desmovilización y la rehabilitación de los niños utilizados como soldados. El consejo se ha comprometido, cuando tome medidas para fomentar la paz y la seguridad, a prestar una atención especial a la protección, los derechos y el bienestar de los niños, examinar los efectos de las sanciones para los niños y a garantizar que el personal que participa en las operaciones de paz reciba una formación adecuada. ${ }^{46}$

Cabe destacar, por otra parte, que el Consejo de Seguridad ha reconocido ya claramente en varias de sus resoluciones y en declaraciones, que las repercusiones perniciosas de los conflictos en los niños tienen consecuencias para la paz y la seguridad. Además de la resolución 1261 que hemos detallado, en las resoluciones del Consejo de Seguridad 1265 (1999) y 1296 (2000) relativas a la protección de los civiles en los conflictos armados, también se ha expuesto de manera similar la particular vulnerabilidad de los niños y la necesidad de tomar medidas especiales para su protección.

El otro mecanismo que finalmente queremos mencionar es el denominado "consultas regionales", llevadas a cabo por la ONU en diferentes regiones y cuyo objetivo en este caso constituía ilustrar el estado actual de la niñez en conflicto en diversas latitudes del mundo. En este sentido, se llevaron a cabo seis consultas en un intervalo de dos años aproximadamente, denominadas: Declaración de la Primera Consulta Regional sobre las Repercusiones de los Conflictos Armados sobre los Niños en el Cuer-

46 Organización de las Naciones Unidas, Documento A/54/430..., cit., nota 19, pp. 17 y 18. Cfr "La resolución 1261 (1999) del Consejo de Seguridad supone un logro histórico para la causa de los niños afectados por los conflictos armados. En primer lugar, es la primera vez en la historia que el Consejo de Seguridad ha dedicado una resolución oficial exclusivamente a la cuestión de la protección de los niños, demostrando así su compromiso con esta causa. En segundo lugar, en la resolución se enuncia una serie de medidas importantes para la protección de los niños que, cuando se apliquen a situaciones concretas, tendrán efectos considerables. En tercer lugar, con la aprobación de la resolución finalmente se ha dado plena 'legitimidad' a la protección de los niños, como cuestión que figura con razón en el orden del día del consejo. En cuarto lugar, el consejo ha pedido al secretario general que le presente a más tardar en julio de 2000, un informe sobre la aplicación de la resolución, indicando así que la cuestión seguirá siendo un tema permanente en su orden del día”, párrafo 68. 
no de África y en África Oriental, Central y Meridional (Addis Abeba, 17 a 19 de abril de 1995); Declaración de la Segunda Consulta Regional sobre las Repercusiones de los Conflictos Armados en los Niños en la Región de los Países Árabes (El Cairo, 27 a 29 de agosto de 1995); Declaración de la Tercera Consulta Regional sobre las Consecuencias de los Conflictos Armados en los Niños en África Occidental y Central (Abidján, 7 a 10 de noviembre de 1995); Declaración de la Cuarta Consulta Regional sobre las Repercusiones de los Conflictos Armados en los Niños en Asia y el Pacífico (Manila, 13 a 15 de marzo de 1996); Declaración de la Quinta Consulta Regional sobre las Repercusiones de los Conflictos Armados en los Niños en la Región de América Latina y el Caribe (Santafé de Bogotá, 17 a 19 de abril de 1996); Declaración de la Sexta Consulta Regional sobre las Repercusiones de los Conflictos Armados en los Niños en Europa (Florencia, 10 a 12 de junio de 1996).

Todas estas consultas generaron un amplio despliegue de especialistas de la ONU, así como expertos independientes, quienes se desplazaron a las diferentes regiones aludidas y tuvieron sesiones de encuentro con fuerzas políticas, sociales y académicas, en aras de formular diagnósticos objetivos de la situación y emitir sendas recomendaciones a seguir. Sin embargo, a juzgar por los acontecimientos presentes, todo quedó en el papel y no en los hechos.

\section{Las iniciativas de protección a la niñez previstas en instrumentos} internacionales y otros acuerdos de aplicación regional

En este apartado vamos a mencionar brevemente algunos acontecimientos que han servido para discernir y aprobar mecanismos de tutela y protección para los niños y niñas en estado de peligrosidad por los conflictos bélicos internos o externos. Abordaremos algunos episodios del ámbito regional europeo y americano, como antecedentes más próximos a nuestras realidades inmediatas.

\section{A. Las iniciativas de protección a los menores en riesgo por asuntos} bélicos en el continente europeo

La Comisión Europea incluyó la protección y la promoción de los derechos del niño, incluidos los del niño soldado, entre las cinco prioridades temáticas de 1999 en el contexto de la iniciativa europea para la 
democracia y los derechos humanos. El Parlamento Europeo celebró audiencias sobre la protección de los niños afectados por conflictos armados, y posteriormente aprobó una resolución en la que apoya la elevación del límite de edad para el reclutamiento y la participación en hostilidades a 18 años. En marzo de 2000, la Asamblea Conjunta de los Estados de África, el Caribe y el Pacífico y la Unión Europea (ACP-UE) aprobó una resolución de carácter general sobre los niños soldados.

En abril de 2000, la Asamblea Parlamentaria del Consejo de Europa celebró tres debates para poner de relieve la creciente necesidad de asegurar los derechos y la protección de los niños en todo el continente. La asamblea acordó que los niños soldados y los jóvenes víctimas del conflicto de Kosovo requerían apoyo especial, y respaldó además los planes para establecer un mediador europeo para los niños.

\section{B. Las resoluciones de la Asamblea General de la Organización de Estados Americanos relativas a los menores en situaciones bélicas}

En el caso del continente americano, debemos decir que antes de la CIDN, todas las legislaciones de menores se inspiraban sin excepción en los principios de la situación irregular. ${ }^{47}$ Una doctrina, que aunque vagamente formulada, marcó decisivamente las legislaciones de "menores" de América Latina, otorgándoles una serie de rasgos característicos. ${ }^{48}$ Una

47 "En pocas palabras, esta doctrina no significa otra cosa que legitimar una acción judicial indiscriminada sobre aquellos niños y adolescentes en situación de dificultad. Definido un 'menor' en situación irregular... se exorcizan las deficiencias de las políticas sociales, optándose por 'soluciones' de naturaleza individual que privilegian la institucionalización o la adopción”. García Méndez, Emilio, "Infancia y derechos humanos", en Nieto Navia, op. cit., nota 1, p. 298.

48 Algunos rasgos centrales de las legislaciones minoristas latinoamericanas serían los siguientes: a) Estas leyes presuponen la existencia de una profunda división al interior de la categoría infancia: niños-adolescentes y menores (entendiéndose por estos últimos el universo de los excluidos de la escuela, la familia, la salud, etcétera). En consecuencia, estas leyes que son exclusivamente de y para los menores tienden objetivamente a consolidar las divisiones aludidas dentro del universo infancia; $b$ ) Centralización del poder de decisión en la figura del juez de menores con competencia omnímoda y discrecional; c) Judicialización de los problemas vinculados a la infancia en situación de riesgo, con la clara tendencia a "patologizar" situaciones de origen estructural; d) Impunidad (con base en una arbitrariedad normativamente reconocida) 
vez, que se empiezan a dar las condiciones para instaurar un instrumento marco de protección de los derechos del niño a nivel internacional, al interior de los países latinoamericanos se gesta una contradicción normativa que hace nugatorios todo un elenco de derechos establecidos en la CIDN. ${ }^{49}$

La Organización de Estados Americanos (OEA), con sede en Washington D. C., más recientemente emite una resolución denominada "Promoción y respeto del derecho internacional humanitario", aprobada en la primera sesión plenaria de la Asamblea General, celebrada el 5 de junio de 2000. Destaca entre sus considerandos que el citado foro esta convencido de que "las mujeres y los niños merecen una protección particular, y acoge con beneplácito la adopción en mayo de 2000 del Protocolo Facultativo de la Convención sobre los Derechos del Niño relativo a la participación de niños en los conflictos armados".

En función de lo anteriormente expuesto, la Asamblea General resuelve lo siguiente:

para el tratamiento de los conflictos de naturaleza penal. Esta impunidad se traduce en la posibilidad de declarar jurídicamente irrelevante los delitos graves cometidos por adolescentes pertenecientes a los sectores sociales medio y alto; $e$ ) Criminalización de la pobreza, disponiendo internaciones que constituyen verdaderas privaciones de libertad, por motivos vinculados a la mera falta o carencia de recursos materiales; f) Consideración de la infancia, en la mejor de las hipótesis como objeto de protección; $g$ ) Negación explícita y sistemática de los principios básicos y elementales del derecho, incluso de aquellos contemplados en la propia Constitución nacional como derecho de todos los habitantes. Ibidem, pp. 296 y 297. En contrapartida, el autor establece una "doctrina de la protección integral" que debe contener una serie de rasgos para las nuevas legislaciones de menores en Latinoamérica. Véase ibidem, pp. 305-307.

49 Alessandro Baratta establece, al respecto, la siguiente semblanza: "A finales de los años 80 y el presente, junto con el proceso de democratización y de pacificación en el área latinoamericana y con el logro que supuso la Convención sobre los Derechos del Niño de la Organización de Naciones Unidas de 1989, la distancia entre la situación jurídica internacional y la nacional ha disminuido a raíz del proceso de ratificación de la convención por parte de los países del área. Sin embargo, se añade ahora en el derecho interno la contradicción entre la norma interna resultante de la ratificación de la convención, y las partes de la legislación y de la praxis administrativa interna, todavía no derogadas pero aún incompatibles con la convención misma. La convención ha puesto entonces fuera de la legalidad internacional e interna buena parte de la legislación y de la praxis administrativa de los Estados ratificantes. Enorme queda todavía en América Latina, después de dos años de su entrada en vigor, la distancia entre la situación real y la situación ideal de la niñez establecida por la convención”, Baratta, Alessandro, op. cit., nota 1, p. 18. 
Exhortar a los Estados miembros que aún lo hubieren hecho a que consideren ratificar o, en su caso, adherir a los protocolos I y II de 1977 adicionales a los Convenios de Ginebra de 1949 y que consideren hacer la declaración contemplada en el artículo 90 del Protocolo I.

Destacar la importancia de que los Estados, de conformidad con las obligaciones jurídicas-internacionales que han asumido tanto en tiempo de paz como en tiempo de conflicto armado, presten especial atención a las siguientes disposiciones:

a) La mayor difusión posible del derecho internacional humanitario entre toda la población, en particular entre las fuerzas armadas y las fuerzas de seguridad, mediante su incorporación en los programas oficiales de instrucción y en la formación de cuadros permanentes de las fuerzas armadas en la materia (artículos 47, 48,127 y 144 de los cuatro Convenios de Ginebra, respectivamente, y los artículos 83 y 11 de los dos protocolos adicionales);

La promulgación de la legislación penal necesaria para sancionar a los responsables de los crímenes de guerra y otras violaciones graves del derecho internacional humanitario (artículos 49, 50, 129, y 146 de los cuatro Convenios de Ginebra, respectivamente, y el artículo 85 del Protocolo Adicional I);

Instar a los Estados miembros que aún no lo hubieren hecho a que, con el apoyo del Comité Internacional de la Cruz Roja, estudien la conveniencia de establecer comités o comisiones nacionales de aplicación y difusión del derecho internacional humanitario.

Esta excitativa se reiteró posteriormente a través de AG/RES. 1771 (XXXI-O/01) del 5 de junio 2001; AG/RES. 1904 (XXXII-O/02) aprobada en la cuarta sesión plenaria celebrada el 4 de junio del 2002. Posterior a estas fechas, tenemos otros antecedentes valiosos, emanados de la misma Asamblea General de la Organización de las Naciones Unidas, y del cual podríamos hacer el siguiente recuento: la resolución AG/RES. 1944 (XXXIII-O/03) de 2003 de la Asamblea General de la OEA instó "a los Estados miembros a que continúen apoyando el trabajo de los comités o comisiones nacionales de asesoramiento u órganos similares encargados de la difusión y aplicación del derecho internacional humanitario donde ya existen, y en los Estados donde no hubiere, a que consideren la conveniencia de establecerlos con el apoyo del Comité Internacional de la Cruz Roja”. El 10 de junio de 2003, la XXXIII Asamblea General de la OEA adoptó la resolución AG/RES. 1944 (XXXIII-O/03) "promoción y respeto del derecho internacional humanitario" en Santiago 
de Chile, en la que se enfatiza la necesidad e importancia de fortalecer el derecho internacional humanitario mediante la aceptación universal de sus instrumentos y la consecuente adopción de las medidas nacionales que son imprescindibles para la efectiva aplicación de los tratados al nivel nacional.

La resolución AG/RES. 1944 (XXXIII-O/03) hace particular referencia a la obligación de sancionar a los responsables de los crímenes de guerra, de resolver el problema de la desaparición de problemas, así como de integrar el derecho internacional humanitario en la doctrina de las fuerzas armadas. Además, insta a los Estados miembros de la organización a que protejan los bienes culturales contra los efectos de los conflictos armados, que garanticen que sus medios y métodos de hacer la guerra sean conforme al derecho internacional humanitario, que contribuyan a encontrar una solución al problema de los residuos explosivos de la guerra, así como al peligro de la disponibilidad sin control de armas pequeñas y ligeras.

La XXXIII Asamblea General adoptó, igualmente, otras resoluciones sobre temas de interés directo para el derecho internacional humanitario. Principalmente las relativas al: Fortalecimiento de los Sistemas de Derechos Humanos en Seguimiento del Plan de Acción de la Tercera Cumbre de las Américas (AG/RES. 1925 XXXIII-O/03); Promoción de la Corte Penal Internacional (AG/RES. 1929 XXXIII-O/03); La Protección de los Derechos Humanos y Libertades Fundamentales en la Lucha contra el Terrorismo (AG/RES. 1931 XXXIII-O/03); Apoyo al Programa de Acción Integral contra las Minas Antipersonal en Centroamérica (AG/RES. 1934 XXXIII-O/03); Apoyo a la Acción contra las Minas en Perú y Ecuador (AG/RES. 1935 XXXIII-O/03); Las Américas como Zona Libre de Minas Terrestres Antipersonales (AG/RES. 1936 XXXIII-O/03); Las Américas como una Región Libre de Armas Biológicas y Químicas (AG/RES. 1966 XXXIII-O/03); La Protección de Refugiados, Repatriados, Apátridas y Desplazados Internos en las Américas (AG/RES. 1971 XXXIII-O/03); Convención Interamericana contra la Fabricación y el Tráfico Ilícitos de Armas de fuego, Municiones, Explosivos y otros Materiales Relacionados (AG/RES. 1972 XXXIII-O/03). ${ }^{50}$

50 Tomado de CICR, Servicio de Asesoramiento en Derecho Internacional Humanitario, Ginebra, Cruz Roja Internacional, 2004, edición en español, pp. 15-17. 


\section{Normativa de tutela a los menores dentro del Sistema Interamericano de Protección a los Derechos Humanos}

En el marco del Sistema Interamericano de Protección a los Derechos Humanos, nos encontramos con que el Protocolo Adicional a la Convención Americana de Derechos Humanos - conocido como Pacto de San Salvador-, recientemente aprobado, ${ }^{51}$ dispone en su artículo 16 los llamados derechos de la niñez:

Todo niño sea cual fuere su filiación tiene derecho a las medidas de protección que su condición de menor requieren por parte de su familia, de la sociedad y del Estado. Todo niño tiene el derecho de crecer al amparo y bajo la responsabilidad de sus padres; salvo circunstancias excepcionales, reconocidas judicialmente, el niño de corta edad no debe ser separado de su madre. Todo niño tiene derecho a la educación gratuita y obligatoria, al menos en su fase elemental, y a continuar su formación en niveles más elevados del sistema educativo.

El nivel de justiciabilidad de esta disposición es altamente programático, al depender de acciones netamente estatales para que se puedan conseguir los derechos o aspiraciones descritos en la norma. Lo importante a rescatar consiste en que el citado artículo establece que todo niño tiene un derecho inherente a su condición de menor, en diferentes niveles, por lo que en el caso de un conflicto armado, estas disposiciones podrían menoscabarse, por lo que es menester asegurar estos derechos irrestrictamente en favor de esta población tan desprotegida.

\section{Jurisprudencia de la Corte Interamericana de Derechos Humanos}

El tema de la protección de los menores como sujetos de derechos, ha presentado un notable avance dentro de la jurisprudencia de la Corte Interamericana de Derechos Humanos, de los últimos años. Anteriormente, sólo conocíamos un asunto en el que este tribunal internacional se ha- 
bía pronunciado con respecto a aspectos en los que fuesen beneficiados con sus proveídos, menores de edad. A solicitud de la Comisión Interamericana, tratándose de los dos niños argentinos Reggiardo Tolosa que habían sido separados de sus verdaderos padres en la época de la dictadura, se requiriere al gobierno de Argentina "la transferencia inmediata de los menores para que los mismos sean puestos en guardia provisoria en un lugar sustituto y sometidos a un adecuado tratamiento psicológico hasta tanto se resuelva la entrega a su familia legítima". ${ }^{52}$

En otro caso sumamente importante - Villagrán Morales y otros contra Guatemala, o mejor conocido como los "Niños de la calle"-, tenemos que mediante sentencia de fondo del 19 de noviembre de 1999, la Corte Interamericana de Derechos Humanos advirtió significativamente que:

A la luz del artículo 19 de la Convención Americana la Corte debe constatar la especial gravedad que reviste el que pueda atribuirse a un Estado parte en dicha convención el cargo de haber aplicado o tolerado en su territorio una práctica sistemática de violencia contra niños en situación de riesgo. Cuando los Estados violan, en esos términos, los derechos de los niños en situación de riesgo, como los 'niños de la calle', los hacen víctimas de una doble agresión. En primer lugar, los Estados no evitan que sean lanzados a la miseria, privándolos así de unas mínimas condiciones de vida digna e impidiéndoles el pleno $\mathrm{y}$ armonioso desarrollo de su personalidad, ${ }^{53}$ a pesar de que todo niño tiene derecho a alentar un proyecto de vida que debe ser cuidado y fomentado por los poderes públicos para que se desarrolle en su beneficio y en el de la sociedad a la que pertenece. En segundo lugar, atentan contra su integridad física, psíquica y moral, y hasta contra su propia vida. ${ }^{54}$

También se encuentra recogido el anterior sentimiento — sea el de optar por una tutela integral y protectiva hacia los menores como sujetos de derechos y deberes - en la Opinión Consultiva de la Corte Interamericana núm. 17 (Condición jurídica y derechos humanos del niño), cuando ésta ubica, en la escala de los valores fundamentales, "la salvaguarda de los ni-

52 Resolución de la Corte Interamericana de Derechos Humanos del 19 de enero de 1994, "Medidas provisionales solicitadas por la Comisión Interamericana de Derechos Humanos respecto de la República Argentina” (caso Reggiardo Tolosa).

53 Al cual se refiere el preámbulo (párrafo 6) de la Convención de Naciones Unidas sobre los Derechos del Niño.

54 Corte IDH, “Caso de los 'niños de la calle' (Villagrán Morales y otros) vs. Guatemala”, Sentencia de 19 de noviembre de 1999, serie C, núm. 63, pp. 78-79, párr. 191. 
ños, tanto por su condición de seres humanos y la dignidad inherente a éstos, como por la situación especial en que se encuentran. En razón de su inmadurez y vulnerabilidad requieren protección que garantice el ejercicio de sus derechos dentro de la sociedad y con respecto al Estado" (párrafo 93).

Además, la Corte Interamericana de Derechos Humanos no titubea en afirmar que todos los seres humanos, independientemente de su condición existencial, son sujetos de derechos inalienables, que le son inherentes (párrafo 41), y en subrayar el imperativo de atender a las necesidades del niño "como verdadero sujeto de derecho y no sólo como objeto de protección" (párrafo 28). La corte en la citada opinión, aduce que solamente a lo largo del siglo XX se articuló el corpus juris de los derechos del niño, en el marco del derecho internacional de los derechos humanos (párrafos 26-27), concebido el niño como verdadero sujeto de derecho. Esta situación ocurrió con el notable impacto de la declaración (1959) y de la convención sobre los derechos del niño (1989), así como de las Reglas Mínimas de las Naciones Unidas para la Administración de la Justicia de Menores (Beijing, 1985), y sobre las Medidas No Privativas de la Libertad (Tokio, 1990), y las Directrices de las Naciones Unidas para la Prevención de la Delincuencia Juvenil (Riad, 1990), además de los tratados generales de derechos humanos.

Nos parece sumamente importante destacar algunas consideraciones vertidas a través del voto separado del magistrado Cançado Trindade, en la opinión que nos ocupa. En primer lugar, se muestra reacio a creer que todavía exista una corriente doctrinal que insista en que la Convención sobre los Derechos del Niño se limita a crear obligaciones estatales: "Esta postura me parece inconvincente y jurídicamente infundada, por cuanto tales obligaciones existen precisamente en razón de los derechos humanos del niño consagrados en aquella Convención de las Naciones Unidas y otros instrumentos internacionales de protección de los derechos humanos". ${ }^{55}$ Desde la perspectiva de este jurista, si se adopta la postura cuestionada, se deja de apreciar precisamente la gran conquista de la ciencia jurídica contemporánea en el presente dominio de protección, a saber, la consagración del niño como sujeto de derecho. 


\section{NECESIDAD DE UNA INSTANCIA JURISDICIONAL DE JUZGAMIENTO DE LAS NORMAS DEL DIH EN FAVOR DE LOS GRUPOS VULNERABLES. LA CORTE PENAL INTERNACIONAL}

La posibilidad de contar con una instancia supranacional que tenga jurisdicción por crímenes que atentan contra todos los valores y derechos humanos de los particulares, tiene su origen en la última década del siglo XX. Desde 1994 se comienza a gestar una serie de negociaciones para establecer un tribunal penal internacional de carácter permanente. Previamente, en 1993 y 1994 se instituyeron dos tribunales especiales para castigar las severas violaciones al DIH, perpetradas en la ex Yugoslavia y Ruanda respectivamente. En el caso de la aspiración de conformación de una instancia suprarregional, el 17 de julio de 1998 se adopta en Roma el Estatuto de la Corte Penal Internacional (CPI), durante la Conferencia de Plenipotenciarios que se celebraba en la capital italiana desde el 15 de junio de ese mismo año. ${ }^{56}$

Vamos a repasar en seguida los antecedentes de los tribunales ad-hoc y la normativa de la CPI, con la finalidad de precisar los alcances y progresos que estos órganos jurisdiccionales han proporcionado a la tutela de grupos selectivos como podría ser la niñez — en el caso de Yugoslavia-, así como lo que se puede esperar sobre este particular de la futura corte penal, tratándose de su jurisdicción con respecto a aquellas faltas producidas a los menores como sujetos vulnerables.

\section{Los tribunales internacionales de crímenes de guerra. Yugoslavia}

El Consejo de Seguridad de las Naciones Unidas decidió la creación del Tribunal Penal Internacional ad hoc para la ex Yugoslavia y aprobó

56 Sobre los antecedentes de esta Corte Penal Internacional, véase a Vargas Carreño, Edmundo, "Una Corte Penal Internacional (aproximación a su proyecto de estatuto preparado por la Comisión de Derecho Internacional)", en Nieto Navia, Rafael (ed.), La corte y el Sistema Interamericano de Derechos Humanos, San José, Costa Rica, Unión Europea-Corte IDH, 1994, pp 537-542; Rodríguez-Villasante y Prieto, José Luis, "Los principios generales de derecho penal en el Estatuto de Roma de la Corte Penal Internacional", en CICR, Servicio de Asesoramiento en Derecho Internacional Humanitario, Adaptación de la Legislación Interna para la Sanción de las Infracciones contra el Derecho Internacional Humanitario, Reunión de Expertos de Países Iberoamericanos, Madrid, 10-12 de marzo de 1999, Ilustre Colegio de Abogados de Madrid-Cruz Roja Española-Plaza Janés, 2000, pp 57-59. 
su estatuto en sus resoluciones 808 del 22 de febrero de 1993 y 827 del 25 de mayo de 1993. Esta iniciativa se suscita en razón del desmembramiento étnico racial de los Balcanes y en particular de la antigua República Federal Socialista de Yugoslavia, que fue unificada por el mariscal Tito en los albores de la Segunda Guerra Mundial, más no pudo subsistir décadas después a las rivalidades entre las poblaciones musulmanas, croatas, kosovares, etcétera, y que habían generado un conflicto étnico de imaginables dimensiones.

Ahora bien, la competencia ratione materiae de este tribunal iba a comprender las infracciones graves a los Convenios de Ginebra, las violaciones de las leyes y usos de guerra, el genocidio y los crímenes de lesa humanidad. ${ }^{57}$ La jurisprudencia de esta instancia jurisdiccional comienza a perfilar los alcances del artículo 3 de su estatuto (leyes y usos de guerra), ${ }^{58}$ cuando la Sala de Apelaciones del tribunal, en una resolución del 2 de octubre de 1995, declara sobre este artículo lo siguiente:

91. El artículo 3 confiere al Tribunal Internacional jurisdicción sobre cualquier ofensa grave al derecho internacional no cubierta por los artículos 2 , 4 o 5 . El artículo 3 es una disposición que prevé que "cualquier violación grave al derecho internacional humanitario" puede ser enjuiciada por el Tribunal Internacional. En otras palabras, el artículo 3 funciona como una cláusula residual diseñada para asegurar que ninguna violación grave al derecho internacional humanitario queda fuera de la jurisdicción del Tribunal Internacional. El artículo 3 persigue hacer esa jurisdicción sin lagunas e inescapable. ${ }^{59}$

Esta resolución empieza a marcar una supremacía normativa dentro del DIH para perseguir delitos de la naturaleza más variada y que afecten

57 Estatuto del Tribunal Penal Internacional para la Antigua Yugoslavia, artículos 2, 3,4 y 5 .

58 "El Tribunal Internacional tendrá competencia para enjuiciar a las personas que violen las leyes o usos de guerra. Dichas violaciones comprenderán lo siguiente, sin que la lista sea exhaustiva: a) El empleo de armas tóxicas o de otras armas que hayan de ocasionar sufrimientos innecesarios; b) La destrucción arbitraria de ciudades, pueblos o aldeas, o su devastación no justificada por necesidades militares; c) Los ataques o bombardeos, por cualquier medio, de pueblos, aldeas, viviendas o edificios indefensos".

59 Citado por Odio Benito, Elizabeth, op. cit., nota 8, p. 281. Véase también lo expuesto por la autora en relación a las condiciones que estableció esta sentencia para aplicar dicho artículo a los conflictos armados internos, en id., op. cit., en esta misma nota, p. 282. 
derechos y deberes consignados en esta jurisdicción especializada. Pensando en la infancia, podríamos decir entonces que la implementación de las normas del DIH que les tutelan en aspectos muy concretos, serían de absoluta ejecutividad o aplicación inmediata según este antecedente.

Con relación a los delitos de lesa humanidad, ${ }^{60}$ y como pueden ser cometidos en contra de la población civil, el Tribunal Penal Internacional clarifica algunas situaciones propicias para entender la gravedad de este ilícito y su posible comisión en contra de las diferentes personas, aún hacia las más indefensas o inofensivas como podrían ser los niños y niñas. ${ }^{61}$ Asimismo, otro de los logros obtenidos en este tribunal de guerra ha sido el de reivindicar una serie de delitos cometidos en perjuicio de poblaciones muy vulnerables, y si se quiere anónimas, en el marco de un conflicto armado: las violaciones e ilícitos sexuales cometidos a las mujeres. ${ }^{62}$ La importancia de este precedente radica en que es perfectamente comunicable a otros grupos igualmente débiles como sería el caso de la niñez y juventud.

Con todas estas resoluciones se va constituyendo no sólo una importante y sólida jurisprudencia que constituye fuente de derecho internacio-

60 Véase sobre este delito lo expuesto en infra epígrafe IV, 2.

61 La Sala I de Primera Instancia (jueces Jorda, Odio Benito y Riad) en el Caso Vukovar, fallado el 3 de abril de 1996, estableció que este tipo de falta debe ser generalizada y sistemática para que se le catalogue como de lesa humanidad. Sin embargo, en el párrafo treinta de dicho proveído se dice que "si hubiere un vínculo con un ataque masivo o sistemático a una población civil, un acto aislado podría calificarse como un crimen de lesa humanidad. De igual modo, un individuo que cometa un crimen contra una sola víctima o un limitado número de víctimas, podría ser declarado como culpable de un crimen de lesa humanidad si sus actos fueren parte de ese especifico contexto antes indicado".

62 Sobre este particular, la ex-jueza Odio Benito nos dice que "el acta de acusación del 17 de junio y el procesamiento del 26 de junio, fechas ambas de 1996 — caso muy conocido por su nombre en inglés Foca indictment-, marcó un hito en la historia del tribunal y del derecho internacional humanitario, por ser la primera vez en que la violación $\mathrm{y}$ otros delitos sexuales no figuran junto con otros cargos, en medio de los cuales terminan por desaparecer, sino que son el motivo central y único de la acusación y el procesamiento", p. 287. Para la autora "es la primera acusación de la historia en donde se reconoce el carácter "genérico" de la violación y otras ofensas sexuales", p. 288. Véase lo expuesto en el Caso Celibi sobre los delitos sexuales y su tipificación como delito internacional humanitario, en Odio Benito, op. cit., nota 8, pp 289-291. 
nal; ${ }^{63}$ sino que además se gesta un antecedente valiosísimo para lo que sería el Estatuto de la Corte Penal Internacional como futuro episodio dentro del DIH.

\section{Los crimenes de DIH previstos en el Estatuto de la Corte Penal Internacional}

El vicepresidente de la Cruz Roja Internacional, doctor Jacques Forster, señala en una reciente reunión de expertos latinoamericanos celebrada en San José de Costa Rica que "La creación de una CPI viene a completar los mecanismos existentes para la aplicación del derecho humanitario y de los derechos humanos y la represión de sus violaciones". ${ }^{64} \mathrm{El}$ artículo 5 del Estatuto de la CPI dispone el juzgamiento de cuatro modalidades o tipos de crímenes:

63 Para precisar qué se entiende por fuentes dentro del derecho internacional, "debe definírselas como los modos de verificación del derecho internacional; o en otras palabras, las fuentes son lo que puede ser invocado como "derecho aplicable" en una relación o situación jurídica" (Vargas Carreño, Edmundo, Introducción al derecho internacional, 2a. ed., San José, Costa Rica, Juricentro, 1994, p. 81). También se ha dicho que son los propios Estados soberanos los que actúan como órganos de producción de las normas, por lo que pueden regular ellos mismos el proceso de creación, modificación y extinción de las reglas del derecho internacional (Camargo, Pedro Pablo, Derecho internacional público, Bogotá, Temis, 1983, p. 29). En todo caso, el artículo 38-1 del estatuto del Tribunal de Justicia dispone cuáles son las fuentes del derecho internacional: "La corte, cuya función es decidir conforme al derecho internacional las controversias que le sean sometidas, deberá aplicar: a) las convenciones internacionales, sean generales o particulares, que establecen reglas expresamente reconocidas por los estados litigantes; b) la costumbre internacional como prueba de una práctica generalmente aceptada como derecho; c) los principios generales de derecho reconocidos por las naciones civilizadas; d) las decisiones judiciales y las doctrinas de los publicistas de mayor competencia de las distintas naciones, como medio auxiliar para la determinación de las reglas de derecho". Para Sorensen, la enumeración de las fuentes sugerida en el anterior artículo presenta tres preguntas generales: "1) Si el orden en que están enumeradas tiene significado alguno, si crea un jerarquía de fuentes o se hizo sólo por conveniencia... 2) hay que preguntarse si la definición de fuentes que enuncia el artículo 38 es de carácter definitivo... 3) Por último, es atinado preguntarse si la relación dada por el artículo 38 es exhaustiva o si aún hay otras fuentes de derecho internacional no mencionadas con él" (Sorensen, Max, Manual de derecho internacional público, $3 \mathrm{a}$. reimpr., México, FCE, 1989, p. 153).

64 Forster, Jacques, "El cincuenta aniversario de los Convenios de Ginebra de 1949: evaluación y perspectivas", Reunión de Expertos Gubernamentales para la Implementación del Derecho Internacional Humanitario dentro del Derecho Nacional, San José, Costa Rica, versión español, 6 de marzo del 2001, p. 12. 


\section{- El crimen de genocidio65}

- Los crímenes de lesa humanidad66

- Los crímenes de guerra ${ }^{67}$

- El crimen de agresión

65 El artículo 6 del estatuto dispone qué se entenderá por "genocidio". Una comisión de expertos estableció: “El genocidio es el 'crimen de todos los crímenes'. Podría considerarse como el más serio de todos los delitos de lesa humanidad. El Estatuto de Roma adoptó la definición de genocidio establecida por la Convención para la Prevención y Represión del Genocidio de 1948”, Corte Penal Internacional, Manual para la ratificación e Implementación del Estatuto de Roma, International Centre for Human Rights and Democratic Development-The International Centre for Criminal Law Reform and Criminal Justice Policy, p. 82. El Sistema de las Naciones Unidas adoptó en la 179 sesión plenaria del 9 de diciembre de 1948, la Convención de Prevención y Sanción del Delito de Genocidio, que fue aprobado por Costa Rica mediante Ley núm. 1205 del 4 de octubre de 1950. Este convenio establece en su artículo primero que "Las Partes Contratantes confirman que el genocidio, ya sea cometido en tiempo de guerra, es un delito de derecho internacional que ellas se comprometen a prevenir y a sancionar". El artículo 2 entiende por genocidio "cualquiera de los actos mencionados a continuación, perpetrados con la intención de destruir, total o parcialmente, a un grupo nacional, étnico, racial o religioso, como tal: a) Matanza de miembros del grupo; b) lesión grave a la integridad física o mental de los miembros del grupo; c) Sometimiento intencional del grupo a condiciones de existencia que hayan de acarrear su destrucción física, total o parcial; d) Medidas destinadas a impedir los nacimientos en el seno del grupo; e) Trasladar por fuerza a niños de un grupo a otro grupo."

66 Estatuto de la Corte Penal Internacional, artículo 7. Para Rodríguez-Villasante y Prieto: "Lo primero que hace el artículo 7 del estatuto es establecer un "umbral" para estos crímenes de la competencia de la corte, puesto que las conductas incriminadas tienen que cometerse como parte de un ataque generalizado o sistemático contra una población civil, siendo destacable que basta que el ataque sea sistemático o generalizado, pues se trata de conductas alternativas, y además se concreta el sujeto pasivo en la población civil, exigiendo el tipo que el sujeto activo tenga conocimiento de que su acción u omisión forma parte de tal programado o masivo ataque", Rodríguez-Villasante y Prieto, op. cit., nota 56, p. 64.

67 Los siguientes comportamientos, los cuales pueden ser tipificados a continuación: 1) Que el acto haya sido cometido durante o en el contexto de un conflicto armado, sin necesidad de distinguir entre los conflictos armados internos y los internacionales; 2) Que el autor del acto esté vinculado a una de las partes del conflicto; este requisito se cumpliría tanto si el perpetrador es militar o civil y la conexión no debe ser necesariamente formal, basta con una demostración material de tal conexión o vínculo; 3) Que la víctima sea una persona que no hubiera tomado parte activa o directa en las hostilidades, o que de haberlo sido, hubiera dejado de serlo, como los miembros de fuerzas armadas que se han rendido o están fuera de combate por enfermedad, detención, heridas, etcétera; citados por Odio Benito, Elizabeth, op. cit., nota 8, p. 280. 
En este sentido, consideramos que la tipificación abordada en este instrumento de punidad internacional es sumamente amplio y contempla diferentes sanciones para sus correspondientes conductas típicas. Así por ejemplo, tenemos que hablando de lesa humanidad el artículo 7, párrafo 2, letras g) y h), establece taxativamente delitos como el de violación; esclavitud sexual; prostitución y embarazo forzado; persecución de un grupo o colectividad con identidad propia, etcétera, entre otros, como una muestra del alcance o cobertura que pueden tener las normas del DIH en este Estatuto de Roma.

Si nos referimos a los crímenes de guerra, el instrumento en estudio es contundente en señalar una serie de acciones tendentes a tutelar la integridad física y humana elemental de las personas. ${ }^{68}$ En el caso de un conflicto armado, se prohíben hacer entre otras cosas ataques intencionales contra la población civil en cuanto tal o contra civiles que no participen dentro de las hostilidades; dirigir ataques contra objetivos no militares; lanzar ataques intencionales a sabiendas que tendrán repercusiones en el medio ambiente; atacar o bombardear por cualquier medio ciudades, aldeas, poblados o edificios que no estén defendidos y que no sean objetivos militares. ${ }^{69}$

Si el conflicto armado no fuera de carácter internacional, no sólo se incluye el artículo 3 común a los CG como parámetro de acatamiento, sino que además se ha dicho que "El estatuto flexibiliza estos requerimientos. No exige que el conflicto involucre necesariamente a las fuerzas armadas de un país ni que exista control efectivo de territorio. Solamente es necesario que exista un conflicto armado prolongado entre las autoridades gubernamentales y grupos armados organizados o entre tales grupos". ${ }^{70}$

\section{Los niños y niñas, y el Tribunal Penal Internacional}

En este apartado, nos vamos a referir sobre distintos aspectos que atañen a los menores, como sujetos de derecho en el marco del procedimiento previsto dentro del Estatuto de la Corte Penal Internacional; así como de aquellas disposiciones previstas para su defensa inmediata.

68 Estatuto de la Corte Penal Internacional, artículo 8, párr. 2, letra a), puntos i) a viii).

69 Ibidem, artículo 8, párr. 2, letra b).

70 Guariglia, Fabricio, "Responsabilidad criminal individual en el Estatuto del Tribunal Penal Internacional para la ex Yugoslavia”, en CICR, Servicio de Asesoramiento..., cit., nota 50, p. 296. 


\section{A. Los niños y niñas como víctimas o testigos}

El artículo 68.1 del estatuto dispone que el tribunal tomará las debidas medidas para proteger la seguridad, el bienestar físico y psicológico, la dignidad y la vida privada de todas las víctimas y testigos. Al hacerlo tendrá en cuenta todos los factores pertinentes, incluidas la edad y la naturaleza del crimen, en particular cuando éste entrañe violencia contra niños. Por su parte, el artículo 36.8.b dispone que los Estados parte tendrán en cuenta la necesidad de que los magistrados sean juristas especializados en temas como la violencia contra los niños. Asimismo, el fiscal debe nombrar — en virtud del artículo 42.9 - asesores jurídicos especializados en esa cuestión, y el artículo 44.1 obliga tanto al físcal como al secretario a tener en cuenta el requisito de la especialización en el tema de la violencia contra los niños, al nombrar al personal a su servicio.

Respecto del artículo 68.2 del estatuto, éste autoriza al tribunal a celebrar a puerta cerrada cualquier parte del juicio o a permitir la presentación de pruebas por medios electrónicos u otros medios especiales con el fin de proteger a los niños que sean víctimas o testigos, a menos que decida no hacerlo atendiendo a todas las circunstancias, en especial a las opiniones de las víctimas o los testigos.

\section{B. La competencia del tribunal para el juzgamiento de menores}

Respecto de la competencia del tribunal para el juzgamiento de niños, el artículo 26 del estatuto dispone expresamente que dicho organismo internacional no tendrá jurisdicción sobre ninguna persona que fuera menor de 18 años en el momento del crimen. Sin embargo, tal disposición no impide que un Estado pueda enjuiciar por genocidio u otros crímenes de lesa humanidad o crímenes de guerra a personas que eran menores de 18 años al momento de cometer el crimen, según lo contemple su propia legislación.

En el caso de los "crímenes que afectan en particular a los niños", el Estatuto de Roma confiere competencia al tribunal para intervenir respecto del genocidio, los crímenes de lesa humanidad y los crímenes de guerra. Sin perjuicio de lo cual se atribuye competencia al organismo respecto de tres crímenes que afectan en particular a los niños: 1) Genocidio por traslado de niños; 2) Crimen de lesa humanidad de tráfico de niños; y 3) Reclutamiento o la utilización de niños soldados en conflictos armados. 
El "genocidio por traslado de niños" incluye expresamente el "traslado por la fuerza de niños del grupo a otro grupo" cuando se realiza con la intención de destruir total o parcialmente a un grupo nacional, étnico o religioso como tal. La definición del crimen de lesa humanidad de esclavitud reconoce que los niños son un grupo especialmente expuesto a este crimen, que se entiende como el ejercicio de los atributos del derecho de propiedad sobre una persona en el tráfico de niños. Pero uno de los logros más significativos en la materia, expresados en el Estatuto de Roma, es que ha hecho posible la inclusión por primera vez en el derecho internacional, del reclutamiento, alistamiento y utilización de niños soldados como crimen de guerra. En virtud del estatuto, reclutar o alistar a niños menores de 15 años en las fuerzas armadas nacionales, en grupos armados o utilizarlos para participar activamente en las hostilidades durante conflictos armados internacionales, constituye un crimen. Habíamos visto, incluso a lo largo de estas líneas, cómo el Protocolo Facultativo a la Convención de Derechos del Niño del 2000 prohibía enlistar en este tipo de actividades a menores de dieciocho años — subsanando lo dispuesto en la convención que tenía el tope hasta los quince años-, por lo cual esta disposición de la CPI viene a reforzar la citada prohibición.

También se han tipificado como crímenes de guerra los ataques intencionados contra, entre otros casos, hospitales y edificios dedicados a la enseñanza. Algunas formas especialmente graves de violencia sexual, incluidas la violación y la esclavitud sexual, son crímenes de guerra y al mismo tiempo crímenes contra la humanidad. En todo caso, el estatuto del Tribunal Penal Internacional presenta aspectos sumamente favorables para enjuiciar a los responsables de cometer crímenes contra la niñez, y de hecho, se ha llamado a la comunidad internacional a movilizarse para apoyar este foro jurisdiccional. ${ }^{71}$

\section{CONSIDERACIONES FINALES}

Hemos querido demostrar que la protección del DIH en la actualidad presenta disposiciones activas de acatamiento obligatorio para la niñez como sector de una población determinada. No obstante, las realidades vi-

71 Véase lo expuesto en Organización de las Naciones Unidas, Documento A/54/430..., cit., nota 19 , p. 15 , párr. 54 . 
vidas durante los conflictos armados han sido duras con los (as) niños (as), incluso dentro de nuestro continente americano, y para ilustrarlo tenemos los casos de Centroamérica y Colombia. ${ }^{72}$ En idéntica forma, se presentan actualmente situaciones sumamente difíciles de violación a los derechos de la niñez en materia de conflictos bélicos, en países tales como Afganistán, Angola, la República del Congo, la República Democrática del Congo, Iraq, Kosovo, Timor Oriental, Sierra Leona, etcétera, en los que la acción de las relatorías especiales nombradas con tal fin por la ONU han tenido un arduo e intenso trabajo.

Consideramos que la creación de tribunales internacionales de guerra y más recientemente una $\mathrm{CPI}$, constituyen un importante precedente para la tutela de los derechos y deberes hacia los civiles en el marco de un conflicto armado. De hecho, la jurisprudencia y las disposiciones estatutarias señalan medidas de protección y ampliación de las diferentes conductas que pueden ser tipificadas como crímenes de guerra, así como otros ilícitos en contra de un sector tan vulnerable como lo es la infancia. Sin embargo, este proceso debe ir acompañado de una serie de pautas que nos permitimos detallar enseguida a manera de corolario.

\section{Necesidad de involucrar a los sujetos afectados con las acciones producidas por la guerra para construir la paz}

En los procesos de establecimiento de la paz, muchas veces los niños han sido olvidados, y el precio de este olvido va manifestándose de manera dolorosa. Sin referencias específicas a los niños durante las negocia-

72 En Guatemala, el $13 \%$ de los infantes y adolescentes menores de 15 años fue asesinado o desaparecido en 1981, mientras que en 1972 se había alcanzado un 19\%. CICR, Revista Región: América Central y el Caribe, Guatemala, 2000, p. 16. En el caso de Colombia, durante más de cuarenta años, los niños colombianos han sufrido como víctimas, testigos y perpetradores de la violencia. En gran número, son soldados en los grupos armados y las fuerzas regulares. Constituyen la mayoría del 1,200,000 personas que se han visto forzosamente desplazadas en el interior de Colombia en los diez últimos años. Las comunidades desplazadas no tienen acceso a los derechos y servicios básicos, como la educación, la salud, el agua y las condiciones de vida higiénicas. La violencia crónica de Colombia ha llevado a niveles alarmantes la prostitución infantil, los enfrentamientos entre pandillas, la violencia en el hogar y el maltrato a los niños, y ha hecho aumentar cada vez más el número de niños de la calle, que con frecuencia son víctimas de la "depuración social". Esa cultura de la violencia ha creado un clima generalizado de temor, impunidad y resignación en la sociedad colombiana. 
ciones de paz, los programas y los recursos para después de los conflictos no se asignarán de la manera pertinente para atender las necesidades de éstos.

El Consejo de Seguridad ha instado a todas las partes en los conflictos a que tengan en cuenta los derechos y la protección de los niños durante las negociaciones de paz. ${ }^{73}$ Así las cosas, el estado de protección de los niños en el futuro, tanto como en su situación presente, debe ser un punto de agenda por resolver, y habría que darle seguimiento en todos los procesos pacificadores en los que intervenga la Organización de las Naciones Unidas y la comunidad internacional organizada en general.

\section{Necesidad de formular politicas desde el Consejo de Seguridad de la ONU para desestimular el armamento en los conflictos internacionales}

Pensar en una eventual paz perpetua como la concebía Kant parece ser un imperativo sumamente difícil de alcanzar en estos tiempos. Después de dejar atrás el conflicto Este-Oeste prevelaciente después de la Segunda Guerra Mundial en el plano geopolítico y militar, las guerras por posesiones de recursos estratégicos - como podría ser el petróleo y sus derivados - , se ha presentado como una nueva dimensión si se quiere "disfrazada" del conflicto entre potencias, que busca expandir sus zonas de influencia.

Propondríamos un gran acuerdo emanado del Consejo de Seguridad, en el que se estimule canjear cooperación internacional por desmantelamiento de los aparatos represivos estatales y particulares, que provean y tengan en su poder armamento para ser utilizado en un conflicto tanto internacional como no internacional. En todo caso, no estamos hablando de nada que no haya sido tratado anteriormente en el seno de la comunidad internacional, y que requiere más voluntad política para ser ejecutado. En julio de 2000, los ministros de Relaciones Exteriores del grupo de países industrializados (conocidos como los “G-8"), en la reunión que celebraron en Okinawa, Japón, publicaron un informe conjunto en el que se reconoce que la suerte de los niños afectados por los conflictos armados es uno de los problemas de seguridad humana más inquietantes a que se enfrenta hoy el mundo y prometieron suprimir los conflictos armados eli- 
minando las armas y el dinero ilícitos que los alimentan en todo el mundo. Los ministros prometieron cooperar con las Naciones Unidas para ejercer presión sobre los perpetradores que intentan captar a los niños en sus conflictos armados o reclutarlos.

Por esta razón, habría que pensar en un "Fondo Cooperativo Compensatorio por Armamento", compuesto por el aporte desinteresado de los países que repudian la guerra y sus nefastas secuelas, bajo un código de convivencia dentro de la sociedad internacional. Estos aportes no sólo pueden estar compuestos prioritariamente con dinero, sino además que se permita a los países denominados pobres o en "vías de desarrollo", brindar su colaboración en los aspectos que pueda hacerlo: personal humano tales como técnicos y profesionales; productos en los que tenga ventaja comparativa y pueda donar, etcétera. La consigna sería que a mayor índice de disminución de armamento, habrá más cooperación como forma retributiva y compensatoria.

\section{Adopción de las normas de jus cogens del derecho internacional humanitario dentro de los respectivos Estados-naciones}

En el plano interior, los países deben enfocar su accionar a conseguir los siguientes objetivos: a) Difusión de reglas y normativa del DIH a través de diferentes medios y dirigido a diversos grupos sociales; b) Adaptación del DIH a la legislación y jurisdicción interna y c) Constitución de Comisiones Nacionales de DIH como las que funcionan en algunos países de Centroamérica y el Caribe. Con todo este proceso codificador lo que se espera es la auto ejecutividad de las normas, en la dimensión interna, y la adhesión a las normativas exógenas que se vayan dando en el ámbito internacional. Paralelamente a lo anteriormente expuesto, es necesario - como bien lo expone el relator especial de las Naciones Unidas - que la comunidad internacional reoriente la atención y la energía que dedicaba a la tarea jurídica del desarrollo de normas hacia el proyecto político de asegurar su aplicación y respeto sobre el terreno: "Es preciso dar inicio a una 'era de aplicación'. Las palabras en el papel no pueden salvar a los niños y las mujeres en peligro. Ese proyecto puede realizarse si la comunidad internacional está dispuesta a emplear su considerable influencia colectiva con ese fin". ${ }^{74}$ 
4. Establecer mecanismos de coordinación entre el Comité de Derechos del Niño y la Corte Penal Internacional

En razón de lo dispuesto en el artículo 38 de la Convención de Derechos del Niño, así como de su Protocolo Facultativo, se hace necesario establecer con carácter de urgencia un tratamiento expedito y sumario a los casos que involucren flagelo a niños y niñas sometidos por un conflicto bélico. Para cumplir este cometido, y en razón de lo expuesto líneas atrás en torno a la competencia del Tribunal Penal Internacional para juzgar crímenes contra la niñez, el Comité de Derechos del Niño debe presentar casos a la CPI en los que se lesionen los intereses y derechos del niño (a) con la finalidad de ir construyendo una vigorosa jurisprudencia que permita la sanción a los culpables de los atroces delitos que se ciernen sobre este grupo vulnerable.

Solamente a través de una acción mancomunada y eficaz se pueden ir superando las barreras de la impunidad que se cierne sobre los crímenes cometidos contra la población menor. En todo caso, nuestra niñez universal, sin distingo de credo, raza ni religión, espera una tutela más efectiva de sus derechos, y el escenario hoy más que nunca es el oportuno para ello. Se hace necesario avanzar hacia mejores estándares de vida y oportunidades de desarrollo para los hombres y mujeres del mañana.

\section{BIBLIOGRAFÍA}

Buergenthal, Thomas, International Human Rights, St. Paul, Minnesota, West Publishing Co., 1995.

et al., Manual internacional de derechos humanos, Caracas-San José, Instituto Interamericano de Derechos Humanos-Editorial Jurídica Venezolana, 1990.

Calvento Solari, Ubaldo, "Protección socio-legal del niño abandonado. Adopción y colocación familiar", Revista Judicial, Costa Rica, año $\mathrm{V}$, núm. 19, mayo de 1981.

Comité Internacional de la Cruz Roja (CICR), Normas Fundamentales de los Convenios de Ginebra y de sus protocolos adicionales, Ginebra, CICR, 1983.

-, Revista Región: América Central y el Caribe, Guatemala, 2000.

-, Servicio de Asesoramiento en Derecho Internacional Humanitario, "Adaptación de la legislación interna para la sanción de las 
infracciones contra el derecho internacional humanitario", Reunión de Expertos de Países Iberoamericanos, Madrid, del 10 al 12 de marzo de 1999, Ilustre Colegio de Abogados de Madrid-Cruz Roja Española-Plaza Janés, 2000.

y Organización de Estados Americanos, "Mesa redonda II. Protección de las niñas y los niños en las situaciones de violencia", Conferencia de Expertos Gubernamentales, San José, Costa Rica, del 6 al 8 de marzo de 2001, CICR, 2002.

— Liga de Sociedades de la Cruz Roja y de la Media Luna Roja, Normas Básicas de Derecho Internacional Humanitario para Uso de Socorristas de la Cruz Roja y de la Media Luna Roja, Ginebra, julio de 1985.

Corte IDH, "Caso de los 'niños de la calle' (Villagrán Morales y otros) vs. Guatemala", Sentencia de 19 de noviembre de 1999, serie C, núm. 63.

, "Condición jurídica y derechos humanos del niño", Opinión Consultiva 17/02 del 28 de agosto de 2002, serie A, núm. 17.

DALWANKAN, Unesh y Comité Internacional de la Cruz Roja (CICR), Simposio sobre Acción Humanitaria y Operaciones de Mantenimiento de la Paz, Ginebra, del 22 al 24 de junio de 1994.

DE PRAUX, Jean, "Derecho internacional humanitario", Revista Internacional de la Cruz Roja, 1985-1989 (separata).

Eguizabal, Cristina et al., Desafíos Humanitarios en Centroamérica. Lecciones de los Conflictos Armados Recientes, San José, Costa Rica, Fundación Arias para la Paz y el Progreso Humano, 1995.

FORSTER, Jacques, "El cincuenta aniversario de los Convenios de Ginebra de 1949. Evaluación y perspectivas", Reunión de Expertos Gubernamentales para la Implementación del Derecho Internacional Humanitario dentro del Derecho Nacional, San José, Costa Rica, 6 de marzo del 2001 (versión española).

FOX, Stanford J., "Beyond the American Legal System for the Protection of Children's Rights", Family Law Quarterly, verano de 1997.

GonzÁlez Volio, Lorena (ed.), Ensayos en honor a Fernando Volio Jiménez, San José, Instituto Interamericano de Derechos Humanos, 1998.

GROS ESPIELL, Héctor, Estudios básicos sobre derechos humanos, Madrid, Civitas, 1988. 
GROSSRIEDER, Jacques, "El derecho internacional humanitario", Instituto Internacional de Derechos Humanos, 26a. Sesión de Enseñanza, Estrasburgo, julio de 1996.

HARroff-TAVEL, Marion, "La acción del Comité Internacional de la Cruz Roja ante las situaciones de violencia interna", Revista Semestral de la Cruz Roja, Ginebra, núm. 17, mayo-junio de 1993.

Nieto NaVia, Rafael (ed.), Estudios básicos de derechos humanos, San José, Costa Rica, Unión Europea-Instituto Interamericano de Derechos Humanos, 1993, vols. II y III.

_ L La corte y el sistema interamericanos de derechos humanos, San José-Costa Rica, Unión Europea, Corte IDH, 1994.

NiKKEN, Pedro, "Los derechos del niño, de los ancianos y de la mujer. Su protección internacional”, Revista IIDH, San José, Costa Rica, Instituto Interamericano de Derechos Humanos, julio-diciembre de 1986.

Organización de las Naciones Unidas, "Promoción y protección de los derechos del niño. Repercusiones de los conflictos armados sobre los niños", Quincuagésimo Primer Periodo de Sesiones, Tema 108 del Programa Provisional, Doc.A/51/306/Add.1, 9 de septiembre de 1996 (versión española, original en inglés).

— Documento A/54/430, 1o. de octubre de 1999 (versión española, original en inglés).

— , Consejo de Seguridad, Informe del Secretario General, Asamblea General del Quincuagésimo Quinto Periodo de Sesiones, Consejo de Seguridad Quincuagésimo Quinto Año, tema 112 del programa provisional "Promoción y protección de los derechos del niño. Los niños y los conflictos armados", A/55/163-S/2000/712, 19 de julio de 2000 (versión española).

PICTET, Jean, Los principios fundamentales de la Cruz Roja, proclamados por la XX Conferencia Internacional de la Cruz Roja, Ginebra, Instituto Henry Durant, 1979.

- Desarrollo y principios del derecho internacional humanitario, Ginebra, Instituto Henry Durant, 1986.

PLATTNER, Denise, "La protección a los niños en el derecho internacional humanitario", Revista Internacional de la Cruz Roja, Ginebra, Suiza, núm. 63, mayo-junio de 1984.

ReUter, Paul, Derecho internacional público, Barcelona, Casa Bosh, 1962. 
Sagastume Gemmell, Marco Antonio, La protección internacional de los derechos de la niñez, Consejo Superior Universitario de Centroamérica, Unión Europea, Guatemala, 2002.

SCHINDLER, Dietrich, "El Comité Internacional de la Cruz Roja y los derechos humanos", Revista Internacional de la Cruz Roja, enero-febrero de 1979.

SINGER, Sandra, "La protección debida a los niños en situaciones de conflicto armado", Revista Internacional de la Cruz Roja, mayo-junio de 1986.

SWINARSKI, Christophe, Introducción al derecho internacional humanitario, Costa Rica, Instituto Interamericano de Derechos Humanos, 1994.

VAlle ItURRIAGA, José Luis, "Proyección de los derechos humanos en el derecho positivo", Ciclo Académico Conmemorativo del XX Aniversario de la Declaración Universal de los Derechos Humanos, Ilustre Colegio de Abogados de Valencia, 1968. 